\title{
ORIENTATION DETERMINATION BY CONTINUOUS ETCHING PATTERNS IN COPPER AND COPPER ALLOYS
}

\author{
W. H. WANG, X. SUN, G. D. KÖHLHOFF and K. LÜCKE \\ Institut für Metallkunde und Metallphysik, RWTH Aachen, Kopernikusstr. 14, \\ 52056 Aachen, F.R.G.
}

(Received 9 March 1995)

\begin{abstract}
A new method for determination of grain orientations using etch patterns was developed for copper and copper alloys. This method is based on the fact, that one gets etch patterns characteristic for the crystallographic orientation of the etched surface, if a specimen of copper or copper alloys is etched in conc. $\mathrm{HNO}_{3}$. In contrast to etch pits, the etch patterns are developed continuously over the whole grain. This allows a direct and continuous observation of the orientation changes within and between the grains, which is not possible for many other orientation determination methods. The determination accuracy of the new method depends on the crystallographic orientation of the etched surface and varies between $2^{\circ}$ and $10^{\circ}$. For some special surface orientations the etch patterns allow even the determination of very small orientation changes $\left(\leq 2^{\circ}\right)$, occurring e.g. in a deformed grain.
\end{abstract}

KEY WORDS: Orientation determination, microtexture, etch pattern, copper

\section{INTRODUCTION}

For many years techniques for measuring texture and characterizing microstructure have been separated, but it has long been realized that a complete description of microstructure must include both local and global textures. While for the determination of global textures scattering techniques for the measuring of e.g. orientation distribution functions (ODFs) are well developed, for determining local textures serious problems may arise. In annealed, coarse-grained material this is possible using a variety of methods, including $\mathrm{X}$-ray micro-beams, etching patterns and Kossel patterns derived from electron back scattering in the scanning electron microscope (SEM), to determine the orientation of each grain, together with optical or electron microscope techniques to measure the grain size, shape and distribution. At the finest level, in principle the scanning transmission electron microscope (STEM) is capable of completely describing both the microstructure and texture of the observed volume, but this is always so small (typically a few micrometres diameter by a fraction of a micrometre thick) that the relation of the measured volume to the global structure and texture is unclear. At a somewhat larger scale techniques based on the SEM become available but these techniques are difficult, and at present the best method, the so-called Electron Back Scattering Pattern (EBSP) technique requires a specially modified SEM and these are available in only a few laboratories.

Thus there is a present requirement in particular for a technique that can provide an overall view of the microstructure and valuable information about the local orientation 

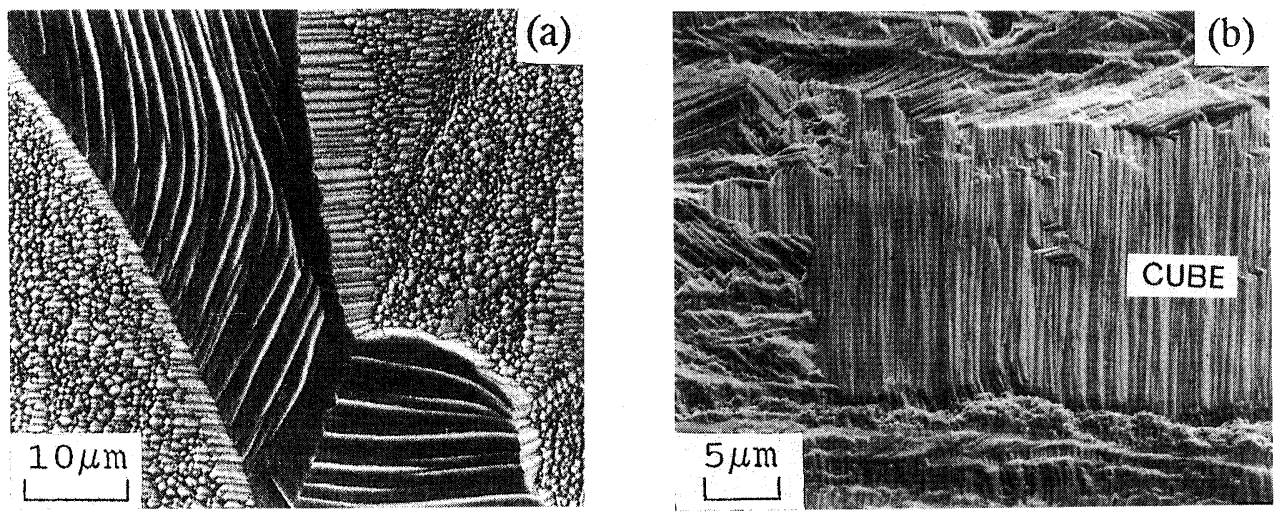

Figure 1 (a) Copper reduced $30 \%$ by rolling. Near many grain boundaries orientation changes take place and in one grain a strong "bending" can be observed. (b) Cube grain in high purity copper, cold rolled by $95 \%$ and annealed for $100 \mathrm{~s}$ at $140^{\circ} \mathrm{C}$ (section in $45^{\circ}$ to rolling plane and longitudinal plane).

at the level at a few micrometres. Such a technique was found several years ago by Köhlhoff et al. (1981), see also Köhlhoff 1989 who observed that single crystals of copper, when prepared by washing in nitric acid prior to X-ray measurements, produced distinct and characteristic etching patterns which could be related unambiguously to the known crystallography of the face. This observation has led to extensive work designed to define the limits of the method as it applies to copper and copper based alloys. The technique has been successfully used in some earlier published work Köhlhoff et al. (1988), Lücke (1990), Duggan and Lee 1985, Duggan et al. (1993).

Moreover, this etching method has proved to have some advantages with great importance for texture research and particularly for the discussion of the underlying physical mechanism of plastic deformation, recrystallization etc. Firstly, since the etching pattern extends continuously over the whole surface of the sample, the orientation changes can be observed continuously. It makes the method superior to most other methods of observation which provide only pointwise orientation data, by observing the continuous orientation changes or the orientation inhomogeneities within a grain and special near the grain boundaries. An example is given in Figure 1a. Secondly, one can readily obtain an overview of the orientations present in areas ranging from macroscopic dimensions down to several $\mu \mathrm{m}$. Finally, orientation determinations can be made on highly deformed materials (true strains up to 3) which is extremely difficult to reach by other methods. As a second example for the capabilities of the method, Figure $1 \mathrm{~b}$ shows the shape of a Cube grain (vertical etching lines) as formed at early stages of recrystallization together with shape and orientation of the surrounding - still deformed - grains Duggan et al. (1993)

The purpose of this paper is to describe the etching method and the way in which orientation is determined along with a brief description of the limitations of the technique. Finally, an atlas of etch figures is presented, which is by far the easiest and quickest way to determine orientation to within a few degrees of accuracy. 

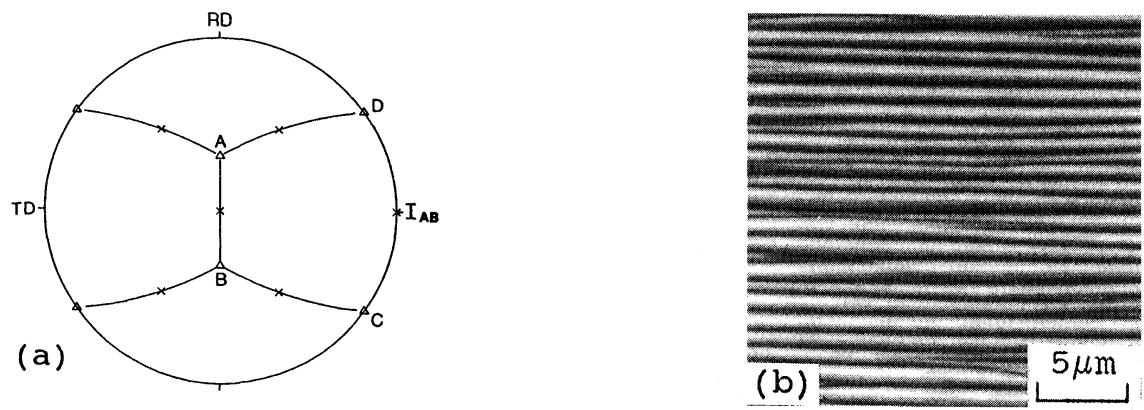

Figure 2 Stereographic projection of $\{110\}<001>$ (a) and corresponding etch pattern in rolling plane (b).

\section{FUNDAMENTALS OF ETCH PATTERN ANALYSIS}

The technique has its basis in the fact that close packed $\{111\}$ planes are exposed by the nitric acid with a relief structure in which the intersections are $<110>$ directions. Figure 2 is a copper crystal of orientation $\{110\}<001>$ (the Goss orientation) which has been etched and examined in the plane perpendicular to $\{110\}$, i.e. the normal direction (ND). The etched pattern consists of a set of regularly spaced lines parallel to the transverse direction (TD) and corresponding to the direction of intersection $\mathrm{I}_{\mathrm{AB}}$ of the planes A and B in Figure 2a. The areas between the lines show the $\{111\}$ planes $\mathrm{A}$ and B. It is important to realize that the dark lines in Figure $1 \mathrm{~b}$ correspond to the valley bottoms in the etched surface. These regions are continually renewed during etching. The ridges between the $\{111\}$ planes are continually attacked and rounded off, they can, hence, not be sharp. The ideal and real sections are shown schematically in Figure 3.

This particularly simple orientation $\{110\}<001>$ allows all $\{111\}$ etch figures to be analyzed. For example if the grain is rotated around ND the only change results from the movement of the direction $A_{A B}$ in the surface. If the grain is rotated about TD towards $\{111\}<112>$ the angle of inclination of the planes to the surface changes and the spacing of the valleys and ridges is no longer constant. At the orientation $\{111\}<112>$ the surface is featureless except for an occasional etch pit. If the crystal is rotated about the rolling direction (RD) the $\langle 110\rangle$ intersections corresponding to $\mathrm{I}_{\mathrm{AB}}$ are tilted out
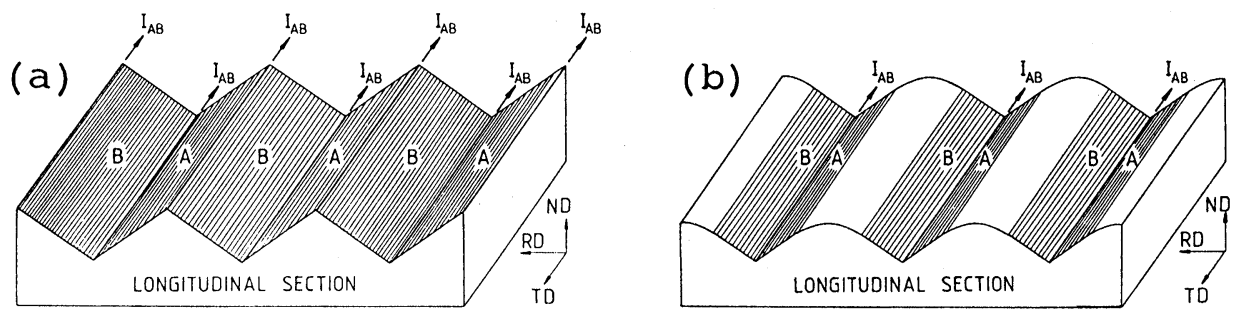

Figure 3 Schematic representation of surface releif (a) ideal and (b) real. 

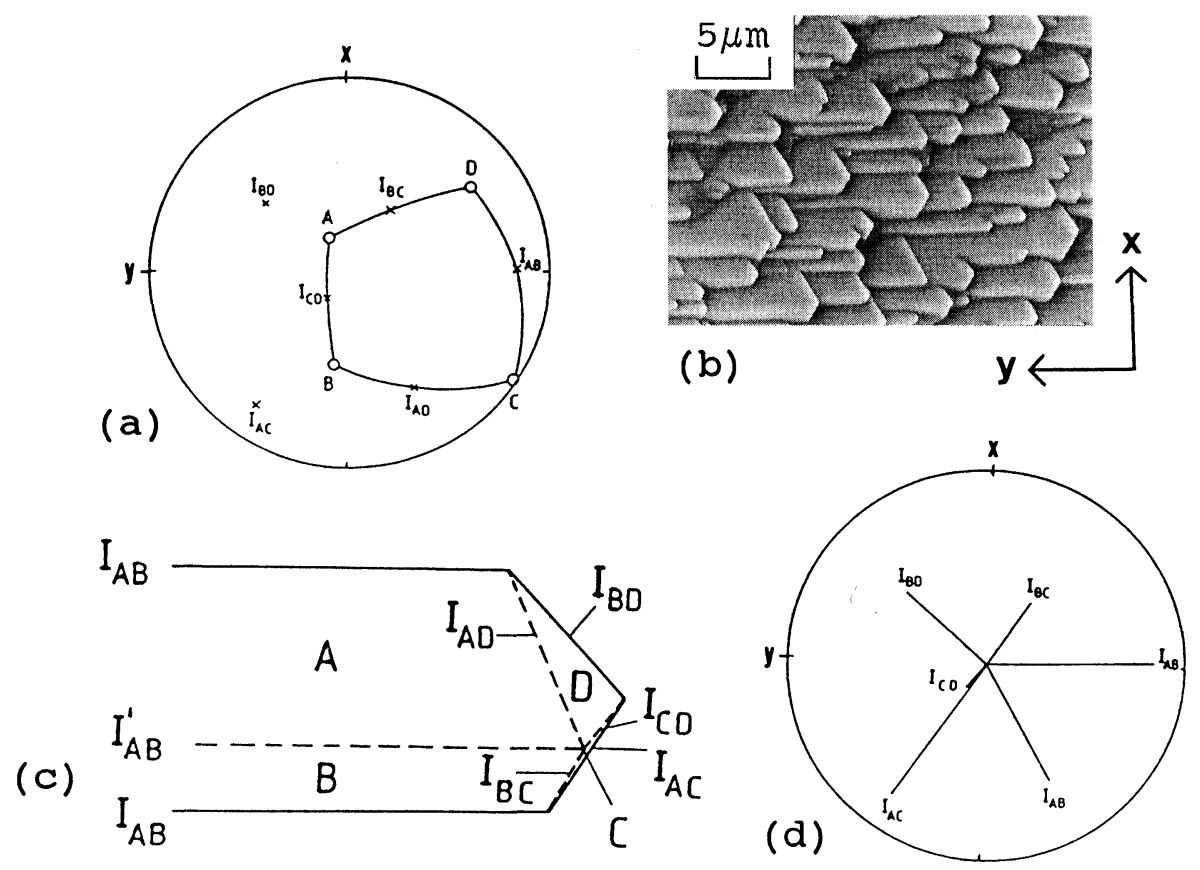

Figure 4 Stereographic projection (a) and corresponding etch pattern (b); schematic representation of a single etch relief (c) and stereographic projection of intersections (d).

of the surface and a series of steps is formed. This is best illustrated by a specific example. Consider a crystal originally in the Goss orientation but then rotated $15^{\circ}$ about TD and subsequently $10^{\circ}$ about the new RD. The orientation of the crystal is shown in Figure 4a and the etched surface in Figure 4b. The dark lines parallel to TD correspond to valleys between the etched planes $\mathrm{A}$ and $\mathrm{B}$; the diffuse white bands between them are derived from the rounded off ridges. The short dark lines are the traces of the intersections between the planes $\mathrm{AC}$ and $\mathrm{BD}$, respectively. The remaining intersections $\mathrm{AD}, \mathrm{BC}$ and $\mathrm{CD}$ are also present as very short diffuse white bands. The positions of all these intersections are shown schematically in Figure 4c. These intersections do not lie in the surface of the specimen and may be tilted by any angle from $0^{\circ}$ to $90^{\circ}$ with respect to that plane. In Figure $4 \mathrm{~d}$ the stereographic projections of the intersections shown in Figure 4c are plotted on the surface plane. The angular relationships to TD are obvious and the angular relationship to ND is related to the length of the lines.

In principle it is possible to determine the orientation of a crystal by means of geometric evaluating of the etch figures in which two traces of planes of known index cut a third plane, but this has been found to be troublesome in the evaluation accuracy because of the roundoff effect of the $<110>$ intersections. The evaluation, besides, takes much effort and is slow compared with the use of standard etch patterns. Such a set of patterns is shown in the Appendix. 


\section{THE TECHNIQUE}

\subsection{Specimen preparation}

Samples are prepared using standard metallographic polishing techniques, usually to the $3 \mu \mathrm{m}$ level, but when dislocation densities are low it is necessary to electropolish. Obviously the best results come from well polished surfaces. Specimens (preferably dry) are dipped into concentrated nitric acid for 1-3 seconds and quickly washed in flowing water before drying in an air draught. The time of etching depends strongly on the acid temperature, which decreases with increasing degree of deformation and alloy content of the material. For example, undeformed pure copper etches best at $\sim 65^{\circ} \mathrm{C}$ while for $95 \%$ cold rolled $\mathrm{Cu}-30 \% \mathrm{Zn}$ the etching temperature is $\sim 20^{\circ} \mathrm{C}$.

In order to prepare samples for the atlas of photographs shown in the Appendix, single crystals of pure copper were sectioned and the face orientation determined to within $2^{\circ}$ by X-ray methods. The etched face was then photographed using a SEM.

\subsection{Determination of Miller indices and Euler angles}

For describing the orientation of the etch figures a Cartesian coordinate system is used with the $x$ - and $y$-axes lying in the etched surface and the $z$-axis perpendicular to it (Figure 4). The orientations are plotted in pole figures and expressed in Euler angles $\left(\varphi_{1}, \phi, \varphi_{2}\right)$ and Miller indices (hkl) [uvw] with the plane (hkl) normal to the $\mathrm{z}$-axis and [uvw] parallel to the $\mathrm{x}$-axis. In this coordinate system the "Cube orientation" (001)[100] is indicated by the Euler angles $\left\{0^{\circ}, 0^{\circ}, 0^{\circ}\right\}$.

As has been mentioned a rotation of the orientation about the z-axis leads only to a rotation of the etching pattern about the surface normal without changing the pattern itself. This means that for each crystallographic plane (hkl) only one standard etch figure needs to be displayed. The others, characterized by different [uvw] or in Euler angle space, by a different $\varphi_{1}$, follow from this by a simple rotation of the etch figure by an angle $\beta$ (Figure 5). Thus it is not necessary to fill the whole three dimensional orientation space with measuring points, but it is sufficient to take a two-dimensional variety of orientations, namely the various (hkl) for plotting the standard etch figures, in other words an inverse pole figure representation is used.

To determine the orientation of an etch pattern using the atlas, a search is made of the standard patterns for the one most similar to the pattern to be determined. Of course, rotations about the $\mathrm{z}$-axis must be first disregarded. The rotation angle $\beta$ is then measured as in Figure 5 for patterns having only a rotational difference about the $\mathrm{z}$-axis and the relationship between the unknown orientation $\left(\varphi_{1}^{\prime}, \phi^{\prime}, \varphi_{2}^{\prime}\right)$ or $\left(h^{\prime} k^{\prime} l^{\prime}\right)\left[u^{\prime} v^{\prime} w^{\prime}\right]$ and the standard orientation $\left(\varphi_{1}, \phi, \varphi_{2}\right)$ or $(\mathrm{hkl})[\mathrm{uvw}]$ is then given by

$$
\varphi_{1}^{\prime}=\varphi_{1}+\beta, \phi^{\prime}=\phi, \varphi_{2}=\varphi_{2}
$$

and

$$
\begin{array}{ll}
\mathbf{u}^{\prime}=\mathrm{u} \cos \beta-\mathrm{q} \sin \beta ; & \mathbf{h}^{\prime}=\mathrm{h} \\
\mathbf{v}^{\prime}=\mathrm{v} \cos \beta-\mathrm{rsin} \beta ; & \mathbf{k}^{\prime}=\mathbf{k} \\
\mathbf{w}^{\prime}=\mathrm{w} \cos \beta-\mathrm{s} \sin \beta ; & \mathbf{l}^{\prime}=\mathbf{l}
\end{array}
$$

Here [qrs] is the orientation of the y-axis of the standard figure. For their multiplication the two vectors [uvw] and [qrs] must be normalized. 


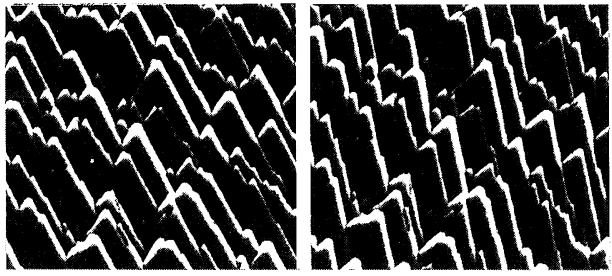

(a)

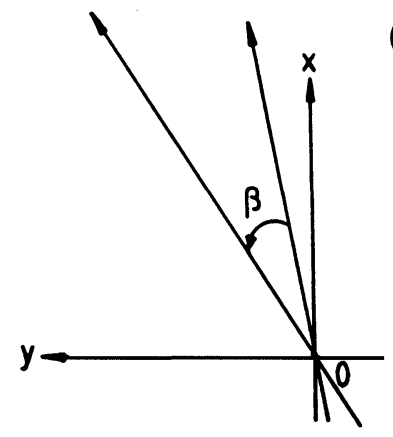

Figure 5 Definition of the rotation $\beta$ between etch figures of the sample (a) and the standard one (b).

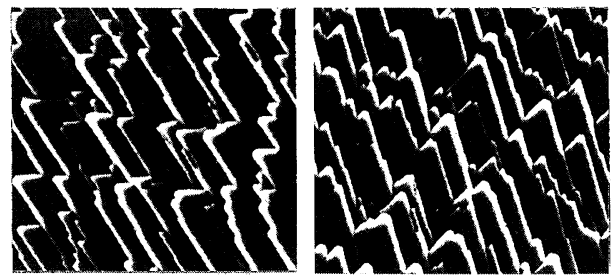

(a)

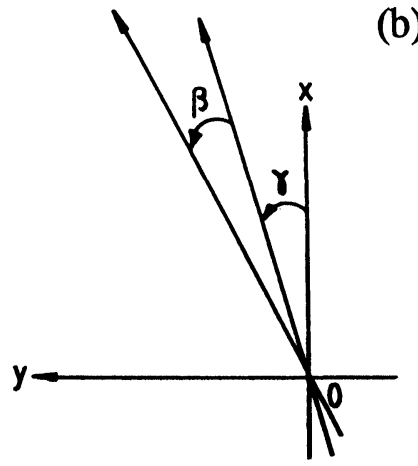

Figure 6 Definition of the angles $\beta$ and $\gamma$ in case that the two pictures are in mirror symmetry.

If the unknown etch figure is additionally mirror symmetric to the standard pattern the $\beta$ angle is determined as above but additionally, the angle $\gamma$ from the $x$-axis to the pattern line used for the $\beta$ measurement in the standard picture has to be determined (Figure 6). $\gamma$ is positive if this shows a counter-clockwise rotation. The orientation of the specimen is then determined as

$$
\varphi_{1}^{\prime}=\beta+2 \gamma-\varphi_{1}, \quad \phi^{\prime}=-\phi, \quad \varphi_{2}^{\prime}=-\varphi_{2}
$$

and

$$
\begin{array}{ll}
\mathrm{u}^{\prime}=\mathrm{u} \cos (\beta+2 \gamma)+\mathrm{q} \sin (\beta+2 \gamma) ; & \mathrm{h}^{\prime}=\mathrm{h} \\
\mathrm{v}^{\prime}=-\mathrm{v} \cos (\beta+2 \gamma)-\mathrm{rsin}(\beta+2 \gamma) ; & \mathrm{k}^{\prime}=-\mathrm{k} \\
\mathrm{w}^{\prime}=\mathrm{w} \cos (\beta+2 \gamma)+\mathrm{s} \sin (\beta+2 \gamma) ; & \mathrm{l}^{\prime}=1
\end{array}
$$

\section{ACCURACY OF ORIENTATION DETERMINATION USING THE ATLAS}

The accuracy of the orientation determination using the etch figures depends essentially on the orientation sensibility of the etching pattern, which is not unique for all surface orientations. In Figure 7 regions of various achievable accuracy are shown in an inverse pole figure (standard triangle), where the orientation of the crystal surface is represented. Close to a $\{111\}$ plane one gets a flat surface with occasional triangle etch pits (orientation 18), with which one can determine the orientation with an accuracy of $\sim 2^{\circ}$. Close to a $\{100\}$ plane one gets crowds of quadratic etch pits sometimes alternated 


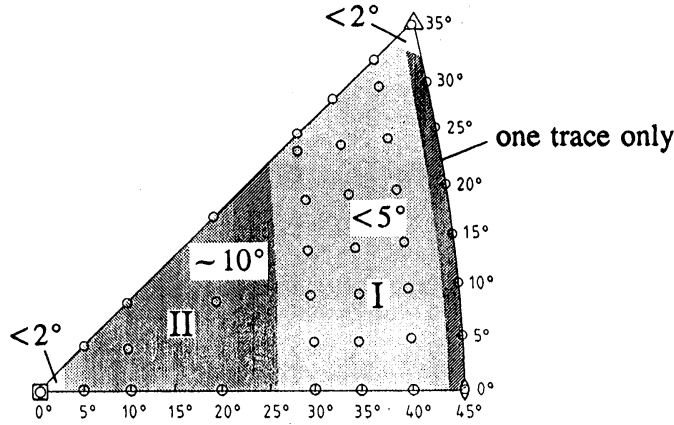

Figure 7 Regions of the orientation accuracy available by the exhibited measuring method.

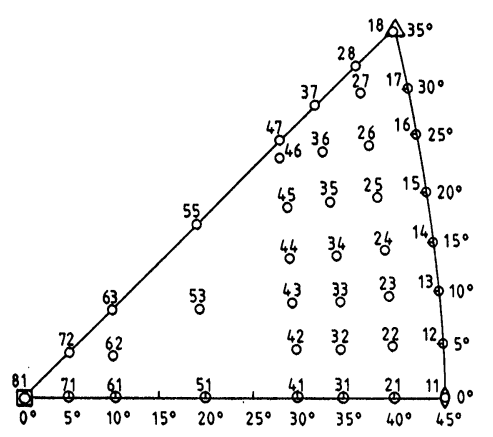

Figure 8 Enumeration of the standard etch patterns in a stereographic traingle in which their surface normals are presented.

with flat areas (orientation 81 ). In this case one can also achieve the orientation accuracy of $\sim 2^{\circ}$.

In the region I of the standard triangle (Figure 7) the orientations can to be determined with an accuracy better than $5^{\circ}$, as it is to be seen in the set of etch figures in the Appendix. But for orientations along the line joining $\{110\}$ to $\{111\}$ the claim for high accuracy is hardly to be sustained, because here only one $\langle 110\rangle$ trace is available. Of course one can determine the surface orientation through measuring the wave length of the dark-light lines, which is, for equal etching depth, dependent on the orientation of the crystal face along this line. However, experimentally it has been shown that it is impossible to obtain equal etching depth, and the plane traces are also difficult to measure. Hence there is some uncertainty along this line.

In the region II (Figure 7) the echting behaviour is markedly changed. One gets here hardly a clear etching pattern, the etched surface is mostly muddled. Besides, the $\{100\}$ planes will be also exposed, as the etched surface lies near it. These make the orientation determination in the region II much more difficult. If possible at all, the accuracy could not be better than $10^{\circ}$.

However, if precise orientation determination is necessary then it is always possible to section samples so that major components of the texture have faces (ND) in the useful part of the standard triangle for accurate orientation determination, and simple stereographic techniques will locate the actual orientation in the reference directions.

Finally, everything so far discussed has treated the plane exposed by etching as flat. any departure from this condition of flatness will produce unexpected variation in orientation determination. This is not a major problem, but it must be considered when, for example the regions close to the grain boundaries are to be observed.

\section{Acknowledgements}

The authors like to thank Dr. W. G. Burchard, Ms. R. Storm and Ms. S. Derichs of the Gemeinschaftslabor für Elektronenmikroskopie of the RWTH Aachen for the experimental assistance. Thanks are also due to Dr. B. J. Duggan, University of Hong Kong, for very helpful discussions. Financial support of the Deutsche Forschungsgemeinschaft is gratefully acknowledged. 


\section{References}

Duggan, B. J. and Lee, C. S. (1989). Proc. 10th RIS $\varnothing$ Int. Symp. on Materials Architecture. Ed.: J. B. Bilde-Soerensen et al. RIS $\varnothing$ Nat. Lab.

Duggan, B. J., Lücke, K., Köhlhoff, G. D. and Lee, C. S. (1993). Acta Met. 1921.

Köhlhoff, G. D. (1989). Doctoral Thesis RWTH Aachen.

Köhlhoff, G. D., Hirsch, J., v. Schlippenbach, U. and Lücke, K. (1981). Proc. ICOTOM-6, Ed.: S. Nagshima, The Iron and Steel Inst. of Japan, Tokyo, 489.

Köhlhoff, G. D., Sun, X. and Lücke, K. (1988). Proc. ICOTOM-8, Ed.: J. S. Kallend and G. Gottstein, TMS Warrendale, 183.

Lücke, K. (1990). In: Electron Microscopy in Plasticity and Fracture Research of Materials. Ed.: U. Messerschmidt et al. Akademie Verlag Berlin, 33.

\section{APPENDIX: ATLAS OF STANDARD ORIENTATIONS}

In the present work 39 standard etch figures are displayed. Their surface orientations (hkl) are shown in Figure 8 . The distances between these points are mostly $5^{\circ}$, but in a region in the centre of the triangle where the appearance of the pattern does not change very much with the orientation, they are about $10^{\circ}$ apart.

The orientations of the standard etching patterns are indicated by numbers of two digits, the first one giving the number of the vertical and the second one of the horizontal row in Figure 8. For each orientation two micrographs with 1000x and 2000x magnifications, together with the corresponding $\{111\}$ pole figure are shown. In the pole figures the circles connecting the nearest 111 poles (dashed lines) and the projections of the different 110 directions (full thin lines) are drawn. The Euler angles (E) and Miller Indices (M) are shown for each etch pattern. 


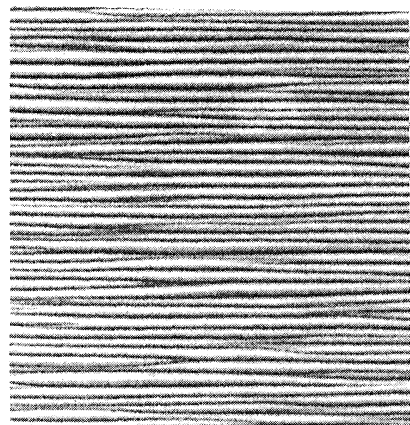

$10 \mu \mathrm{m} \equiv$ orientation orientation 11
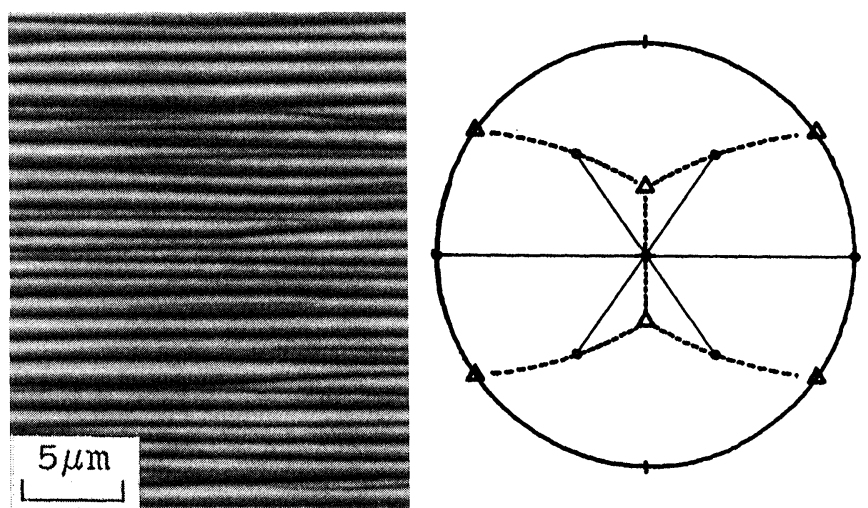

E: $\quad 0.0 \quad 45.0 \quad 90.0$

M: $\quad\left(\begin{array}{ll}1 & 0\end{array}\right.$

1) $\left[\begin{array}{lll}0 & -1 & 0\end{array}\right]$

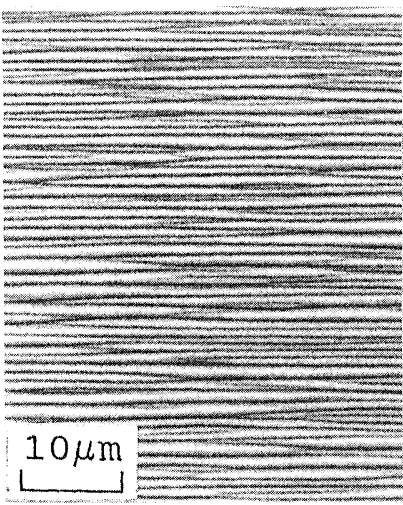

Orientation 12
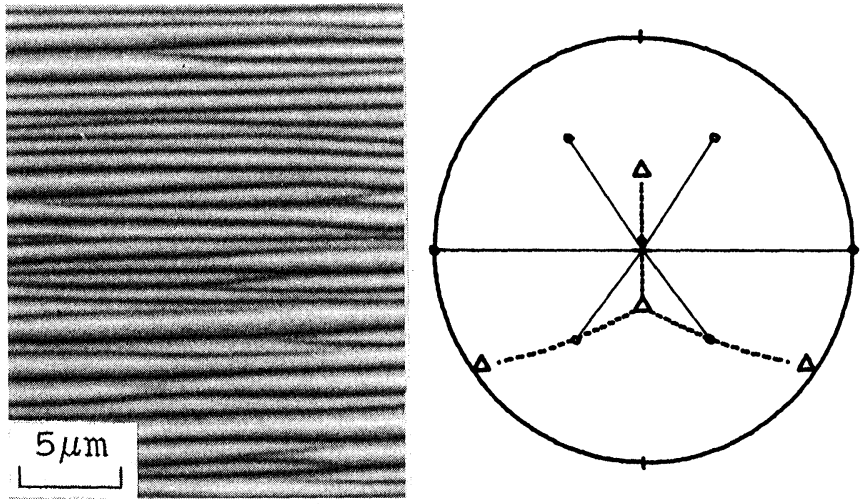

E: $\quad 5.2 \quad 45.2 \quad 82.7$

$M:\left(\begin{array}{lll}70 & 9 & 70\end{array}\right) \quad\left[\begin{array}{lll}6 & -100 & 6\end{array}\right]$
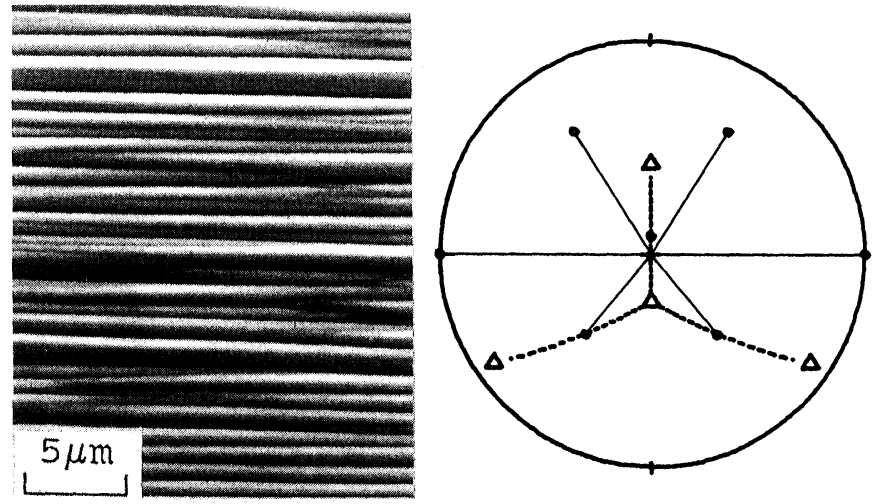

E: $\quad 9.6 \quad 45.8 \quad 76.4$

M: $\left(\begin{array}{lll}70 & 17 & 70\end{array}\right) \quad\left[\begin{array}{lll}12 & -99 & 12\end{array}\right]$ 


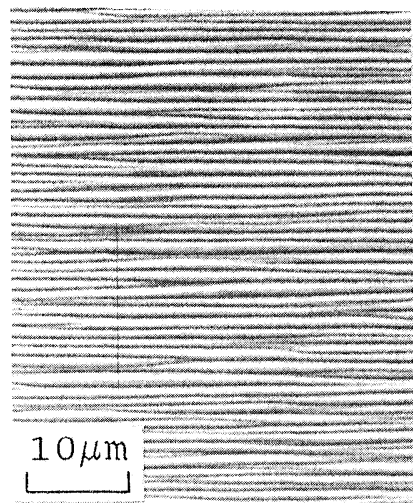

Orientation 14

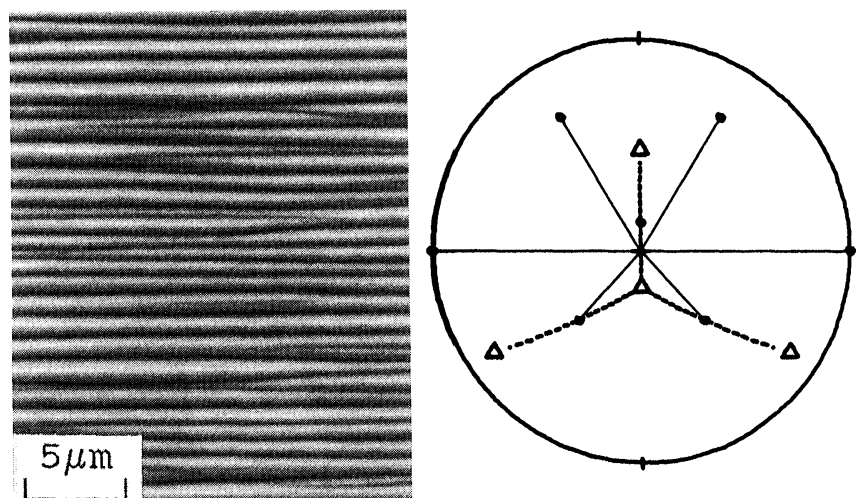

$1=$

$$
\text { E: } \begin{array}{llll}
14.6 & 47.0 & 69.1
\end{array}
$$

$$
\text { M: }\left(\begin{array}{lll}
68 & 26 & 68
\end{array}\right)\left[\begin{array}{lll}
18 & -97 & 18
\end{array}\right]
$$
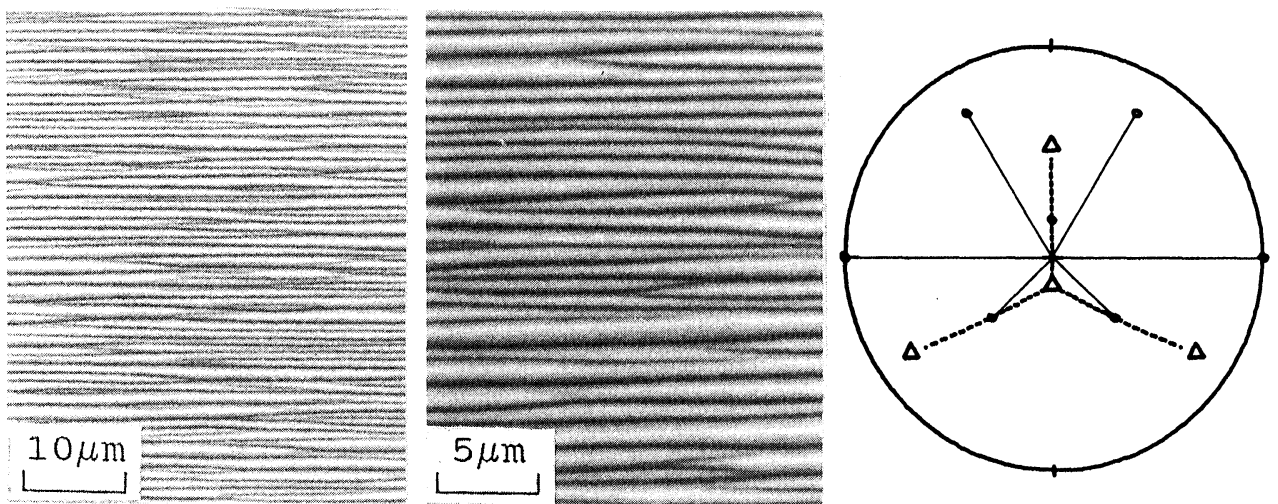

$\begin{array}{lllll}\text { Orientation } 15 & \text { E: } & 18.9 & 48.4 & 62.7\end{array}$

$$
\text { M: }\left(\begin{array}{lll}
66 & 34 & 66
\end{array}\right)\left[\begin{array}{lll}
24 & -94 & 24
\end{array}\right]
$$

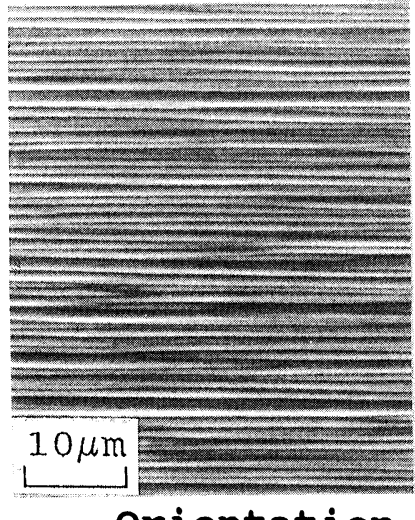
orientation 16
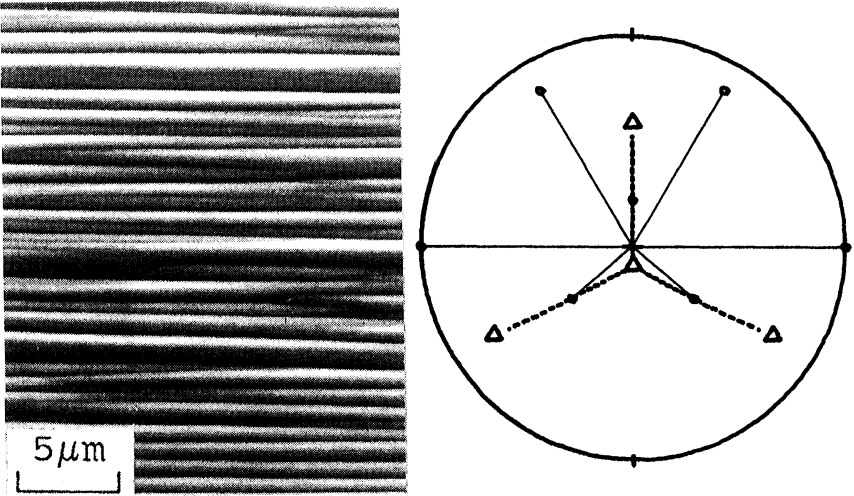

$\begin{array}{llll}\text { E: } & 22.8 & 50.1 & 56.7\end{array}$

M: $\left(\begin{array}{lll}64 & 42 & 64\end{array}\right) \quad\left[\begin{array}{lll}30 & -91 & 30\end{array}\right]$ 

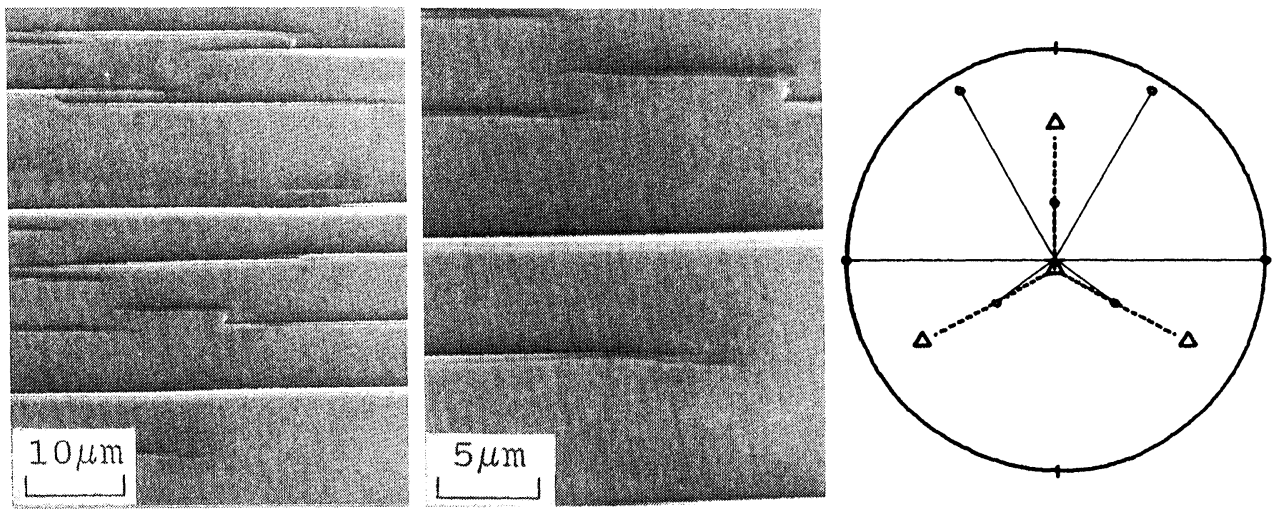

orientation 17

$\begin{array}{llll}\text { E: } & 26.6 & 52.3 & 50.7\end{array}$

M: $\left(\begin{array}{lll}61 & 50 & 61\end{array}\right) \quad\left[\begin{array}{lll}35 & -87 & 35\end{array}\right]$
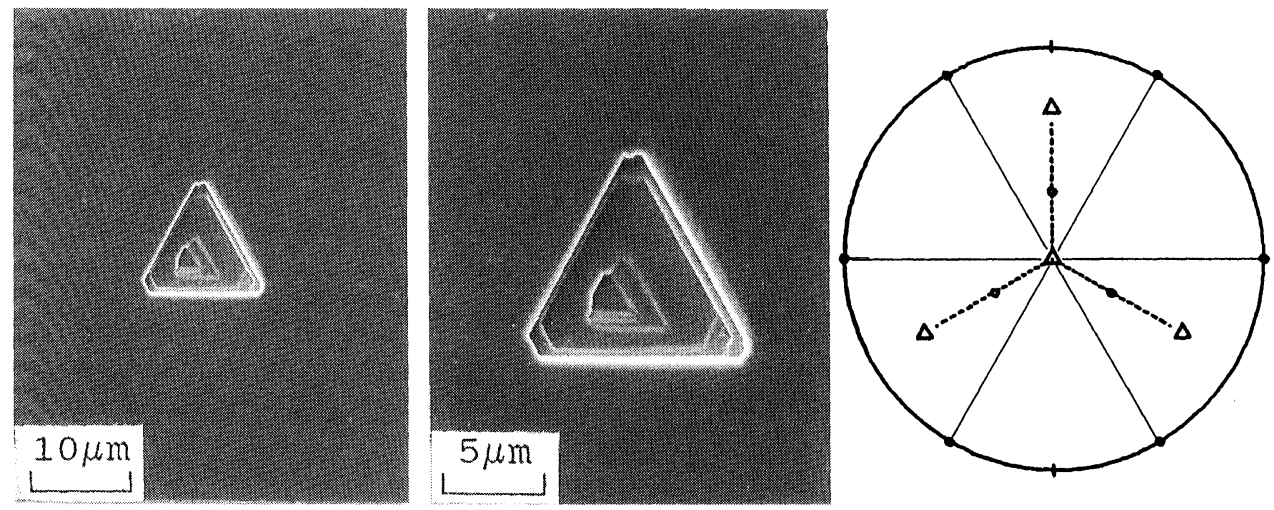

orientation 18

E: $\quad 30.0 \quad 54.7 \quad 45.0$

M: $\left(\begin{array}{lll}1 & 1 & 1\end{array}\right)\left[\begin{array}{lll}1 & -2 & 1\end{array}\right]$
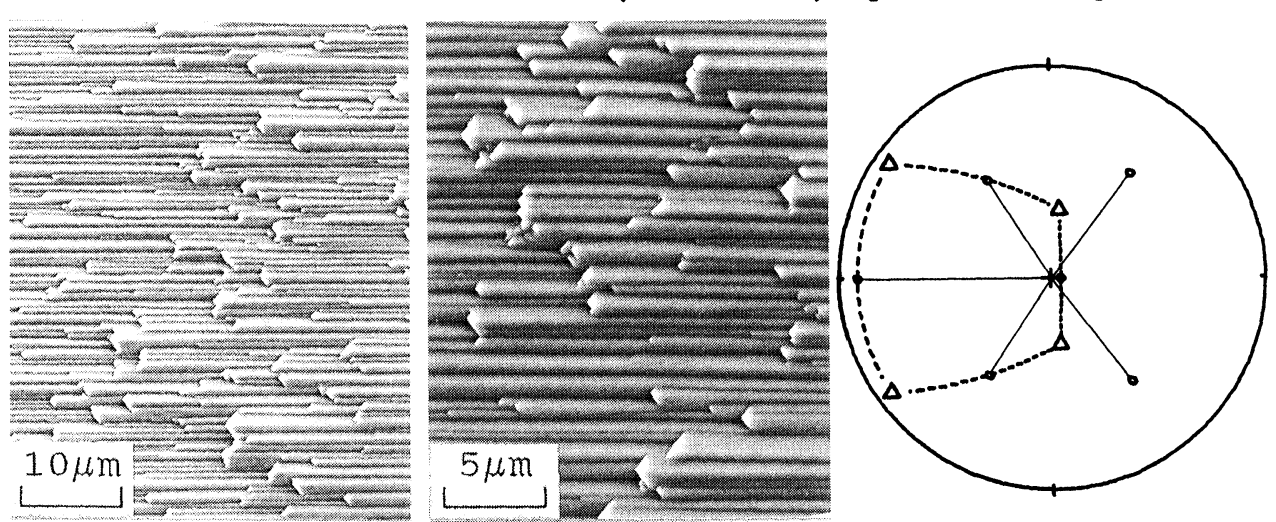

Orientation 21

E: $\quad \begin{array}{llll}0.0 & 50.3 & 90.0\end{array}$

M: $\left(\begin{array}{lll}77 & 0 & 64\end{array}\right) \quad\left[\begin{array}{lll}0 & -1 & 0\end{array}\right]$ 

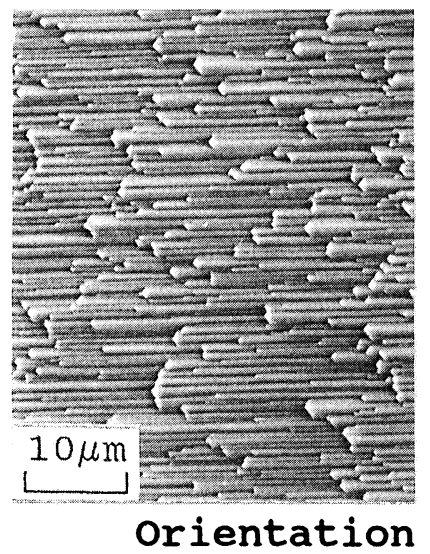
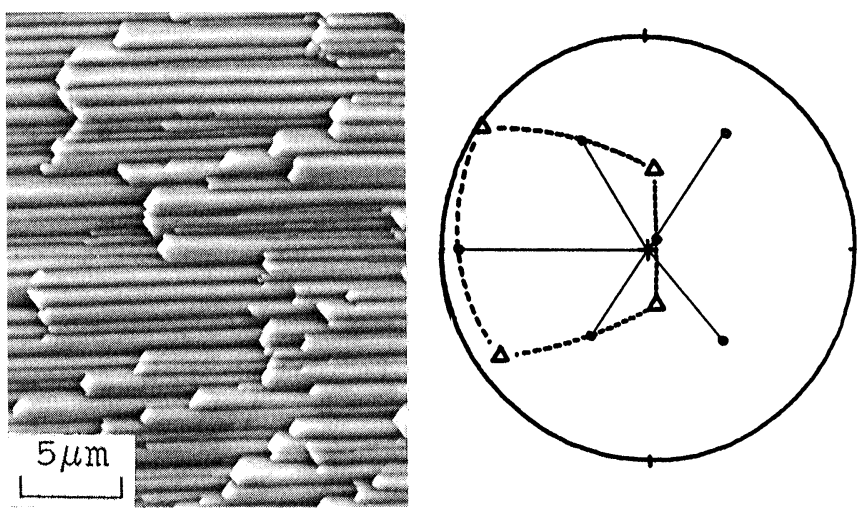

$\begin{array}{llll}E: & 4.8 & 50.1 & 83.3\end{array}$

M: $\left(\begin{array}{lll}76 & 9 & 64\end{array}\right)\left[\begin{array}{lll}6 & -100 & 6\end{array}\right]$
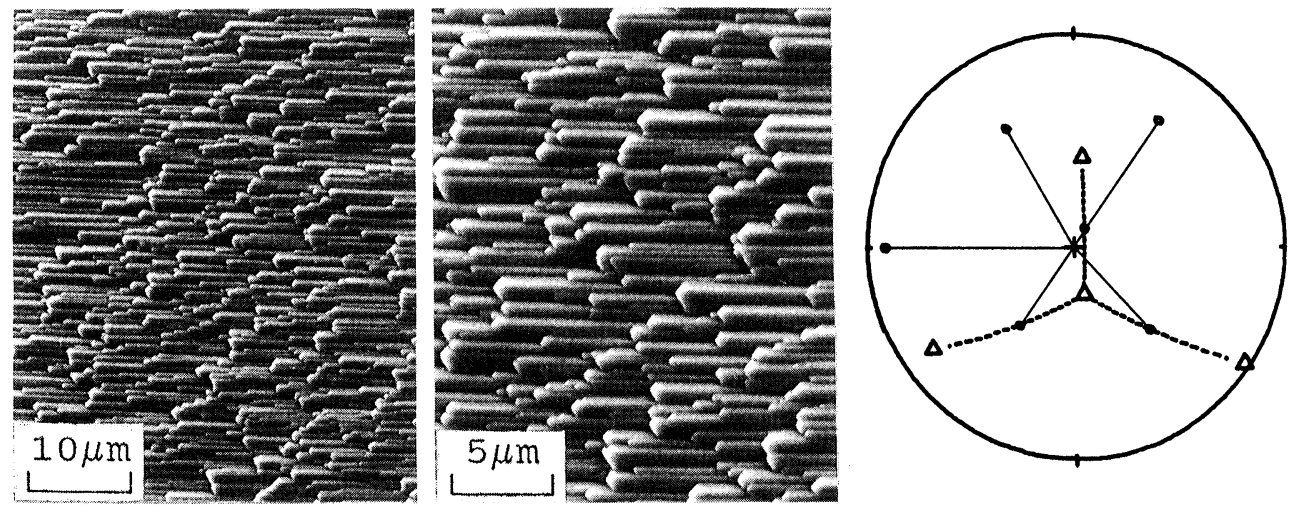

Orientation 23

E: $\quad 8.9 \quad 51.0 \quad 77.4$

M: $\left(\begin{array}{lll}76 & 17 & 63\end{array}\right) \quad\left[\begin{array}{lll}12 & -99 & 12\end{array}\right]$
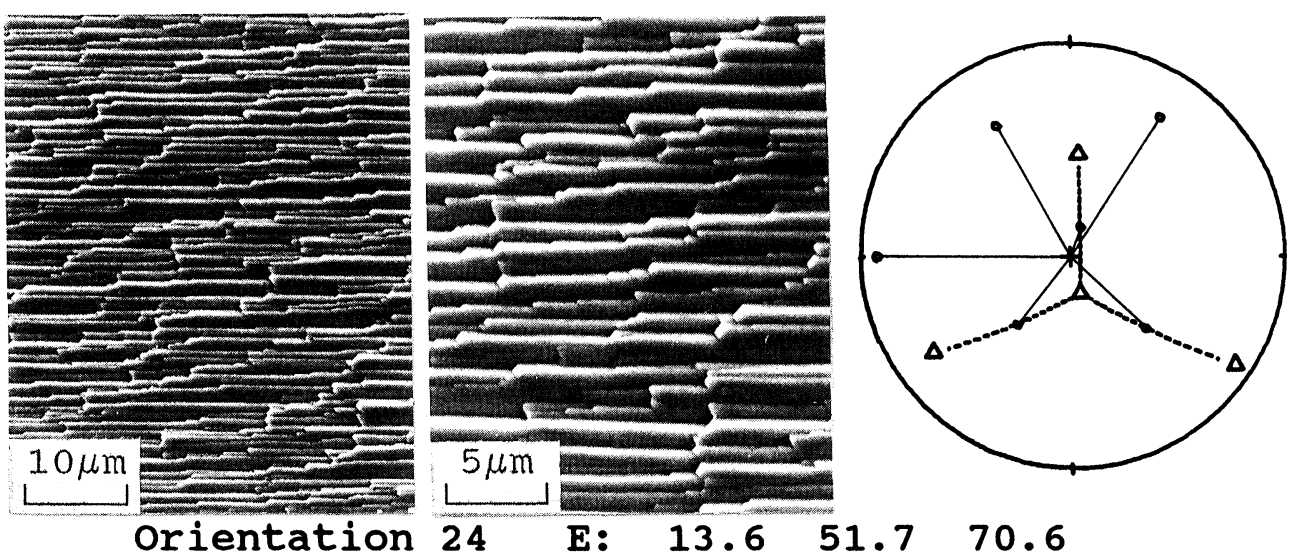

E: $\quad \begin{array}{llll}13.6 & 51.7 & 70.6\end{array}$

M: $\left(\begin{array}{lll}74 & 26 & 62\end{array}\right)\left[\begin{array}{lll}18 & -97 & 18\end{array}\right]$ 

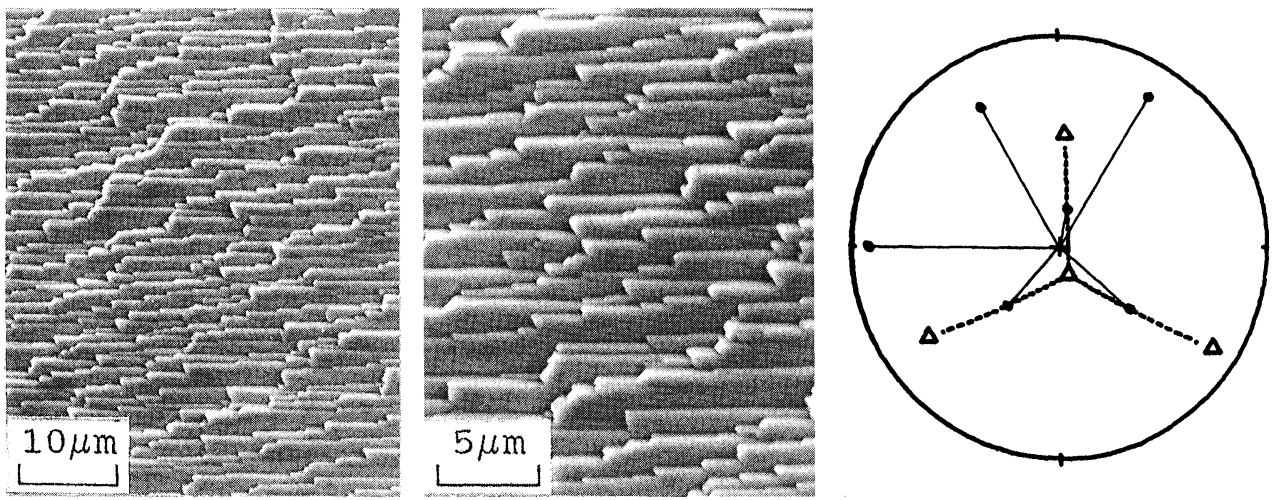

$$
\begin{array}{llllll}
\text { Orientation } 25 & \mathrm{E}: & 17.6 & 53.0 & 64.7 \\
& \mathrm{M}: & \left(\begin{array}{lllll}
72 & 34 & 60
\end{array}\right) & {\left[\begin{array}{llll}
24 & -94 & 24
\end{array}\right]}
\end{array}
$$
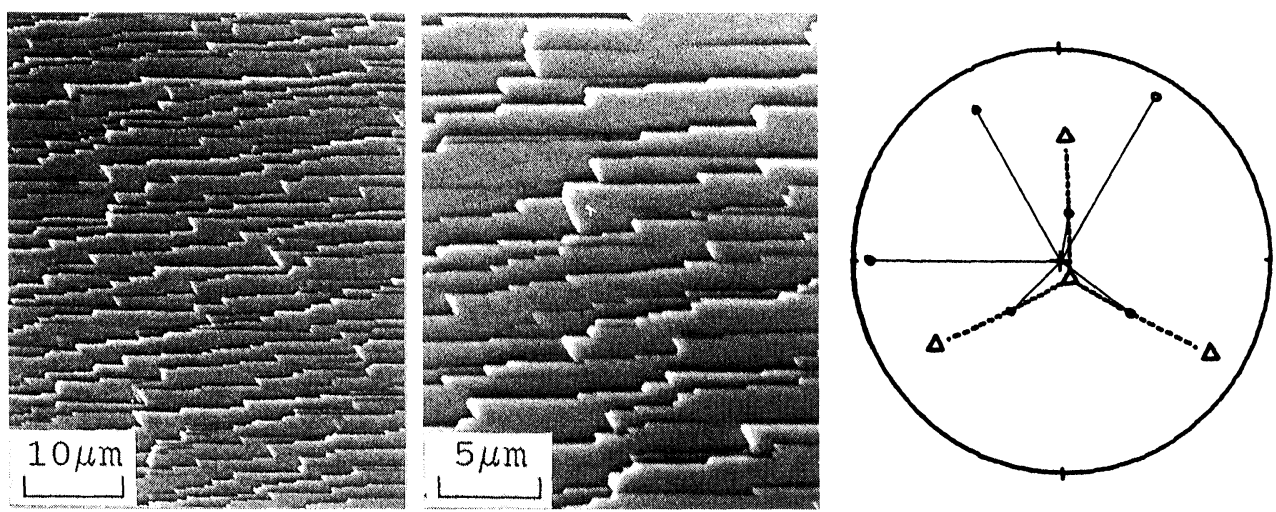

orientation 26

E: $\quad 21.4 \quad 54.6 \quad 59.0$

M: $\left(\begin{array}{lll}70 & 42 & 58\end{array}\right) \quad\left[\begin{array}{lll}30 & -91 & 30\end{array}\right]$

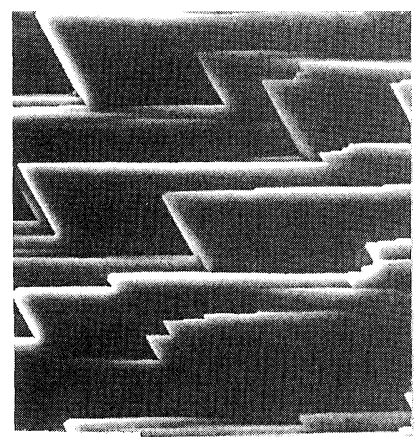

$10 \mu \mathrm{m}$ orientation 27
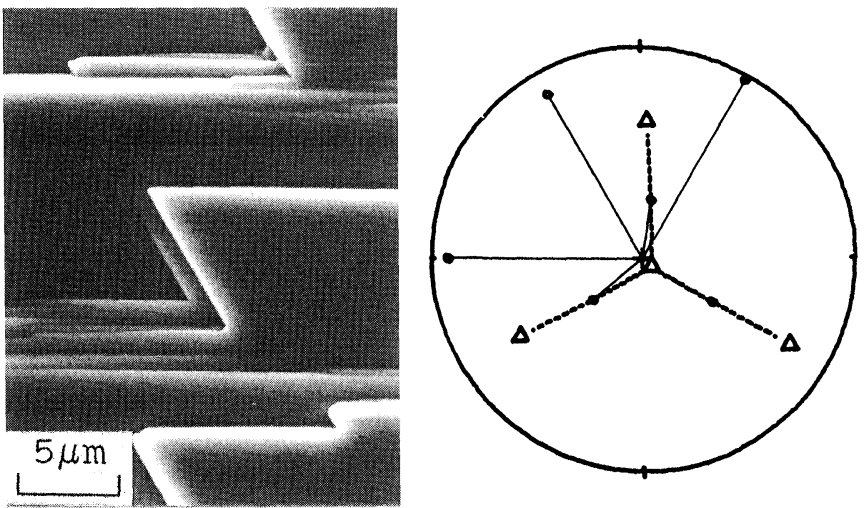

$\begin{array}{llll}\text { E: } & 25.1 & 56.7 & 53.3\end{array}$

M: $\quad\left(\begin{array}{lll}67 & 50 & 55\end{array}\right) \quad\left[\begin{array}{lll}35 & -87 & 35\end{array}\right]$ 

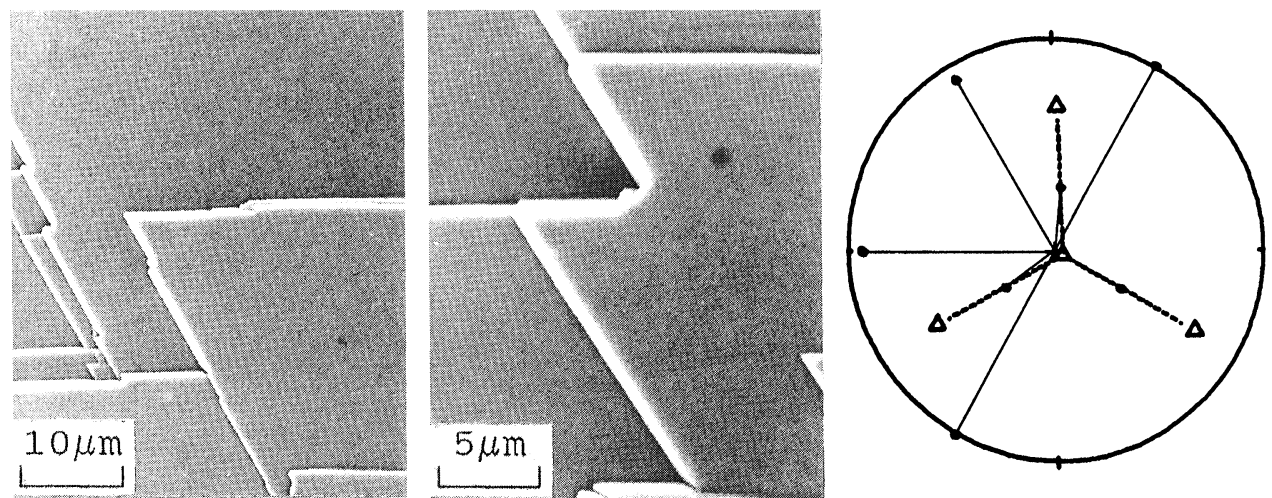

Orientation 28

$\begin{array}{llll}\text { E: } & 27.2 & 57.2 & 49.8\end{array}$

M: $\quad\left(\begin{array}{lll}64 & 54 & 54\end{array}\right) \quad\left[\begin{array}{lll}38 & -84 & 38\end{array}\right]$
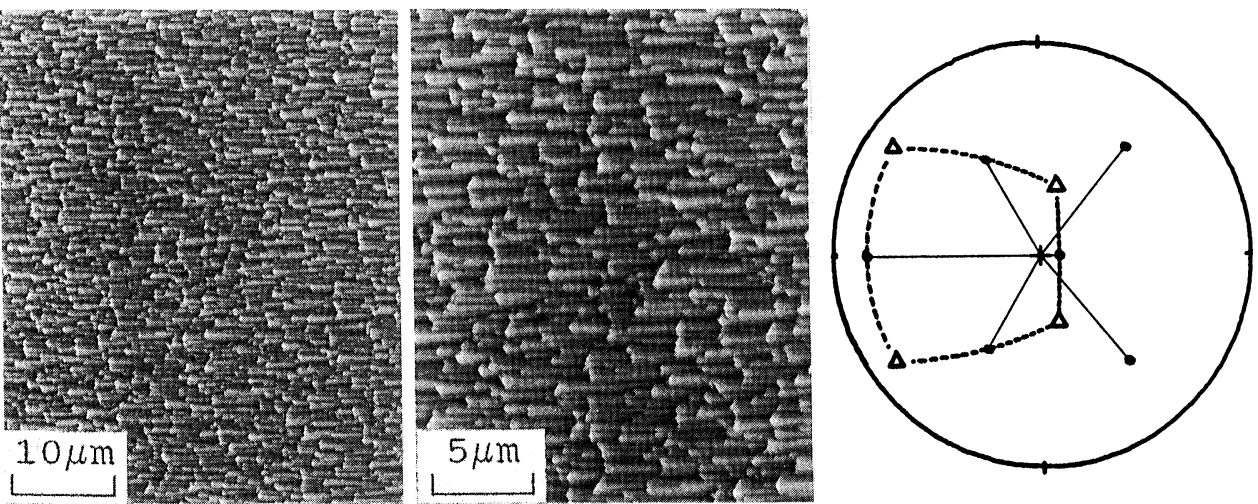

orientation

31

E: $\quad 0.0 \quad 55.2 \quad 90.0$

M: $\left(\begin{array}{lll}82 & 0 & 57\end{array}\right)\left[\begin{array}{lll}0 & -1 & 0\end{array}\right]$
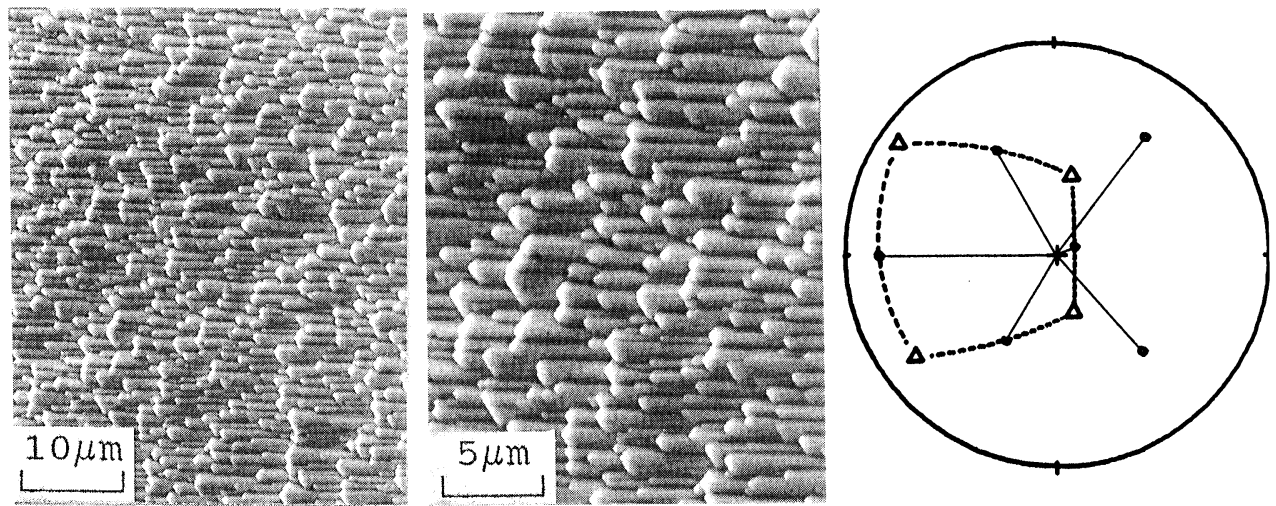

Orientation 32

$$
\begin{aligned}
& \begin{array}{llll}
\text { E: } & 4.0 & 55.3 & 84.4
\end{array} \\
& \text { M: }\left(\begin{array}{lll}
82 & 8 & 57
\end{array}\right)\left[\begin{array}{lll}
6 & -100 & 6
\end{array}\right]
\end{aligned}
$$



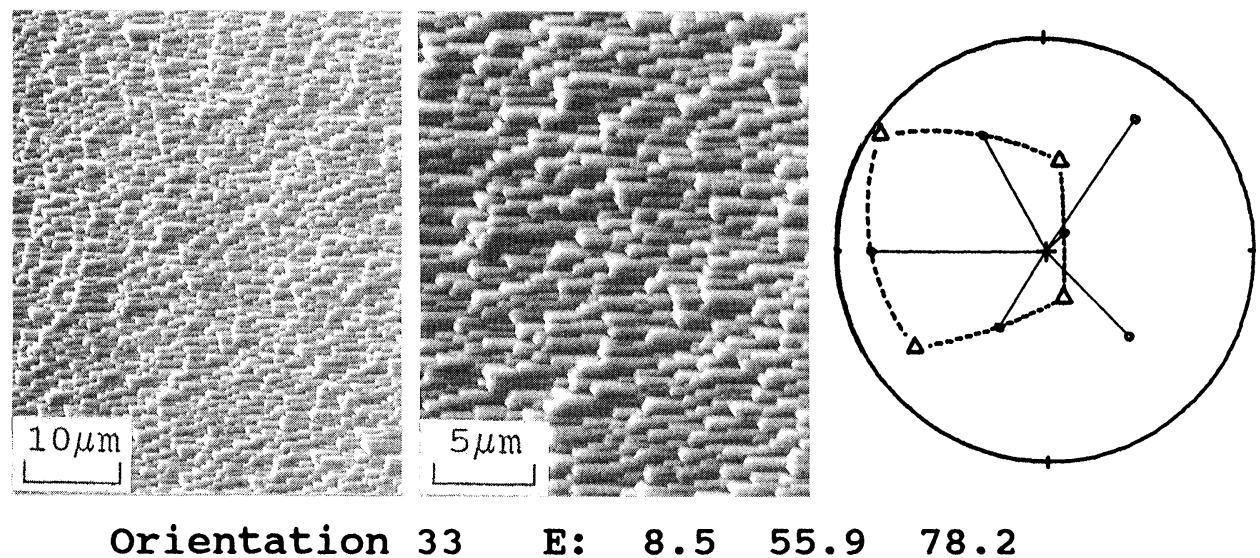

33

E: $\quad 8.5 \quad 55.9 \quad 78.2$

M: $\left(\begin{array}{lll}81 & 17 & 56\end{array}\right) \quad\left[\begin{array}{lll}12 & -99 & 12\end{array}\right]$
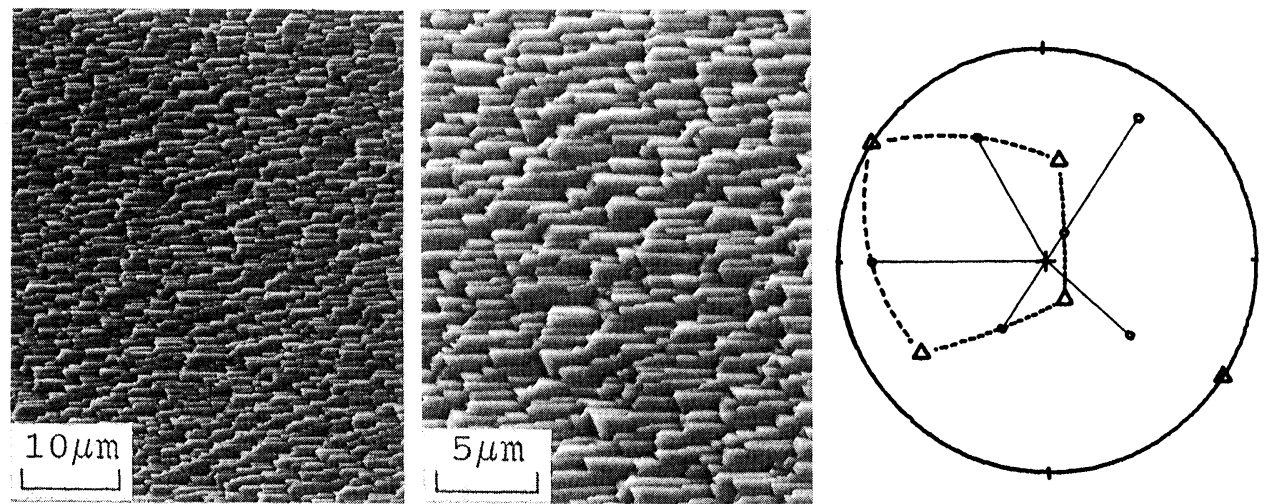

orientation 34

E: $\quad \begin{array}{llll}12.4 & 56.7 & 72.7\end{array}$

M: $\left(\begin{array}{lll}80 & 25 & 55\end{array}\right) \quad\left[\begin{array}{lll}18 & -97 & 18\end{array}\right]$
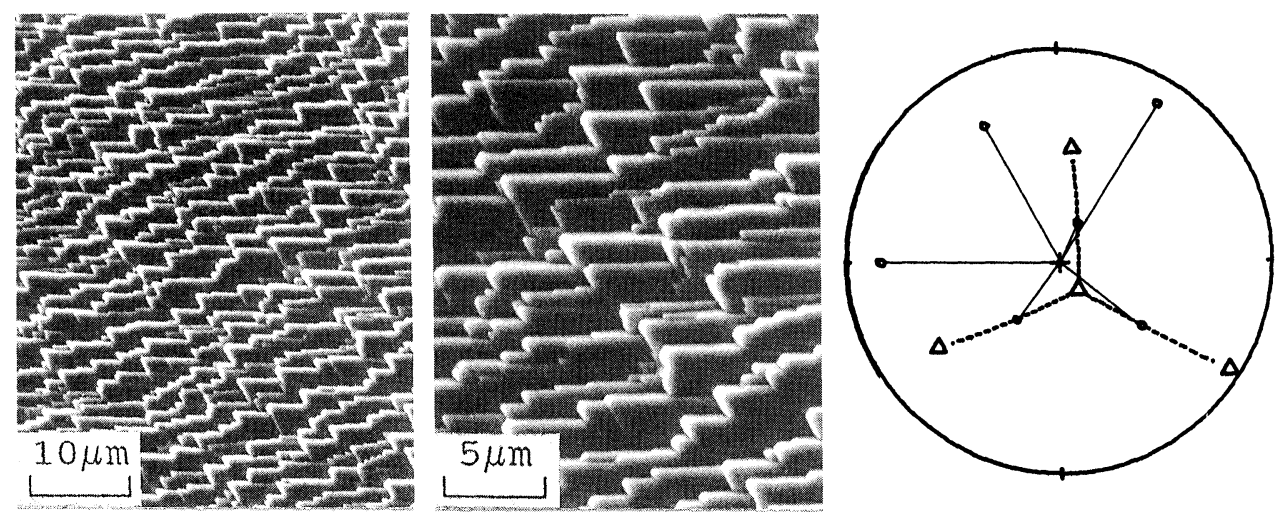

orientation $35 \quad$ E: $\quad \begin{array}{llll}16.6 & 58.1 & 66.5\end{array}$

M: $\left(\begin{array}{lll}78 & 34 & 53\end{array}\right) \quad\left[\begin{array}{lll}24 & -94 & 24\end{array}\right]$ 

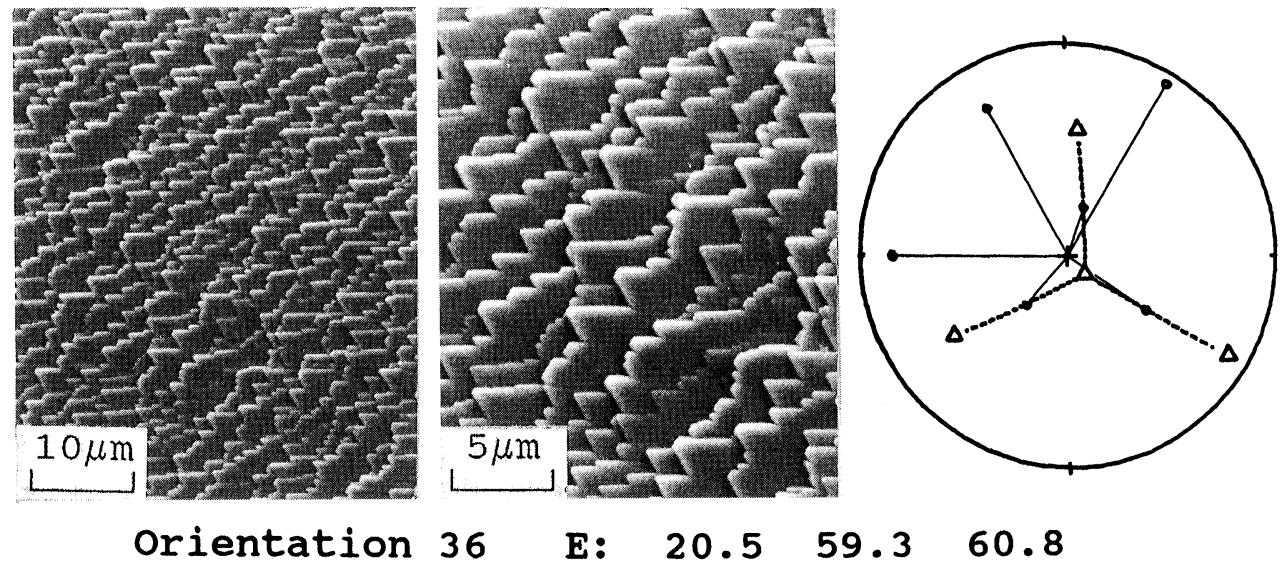

\section{6}

$\begin{array}{llll}E: & 20.5 & 59.3 & 60.8\end{array}$

M: $\left(\begin{array}{lll}75 & 42 & 51\end{array}\right) \quad\left[\begin{array}{lll}30 & -90 & 30\end{array}\right]$
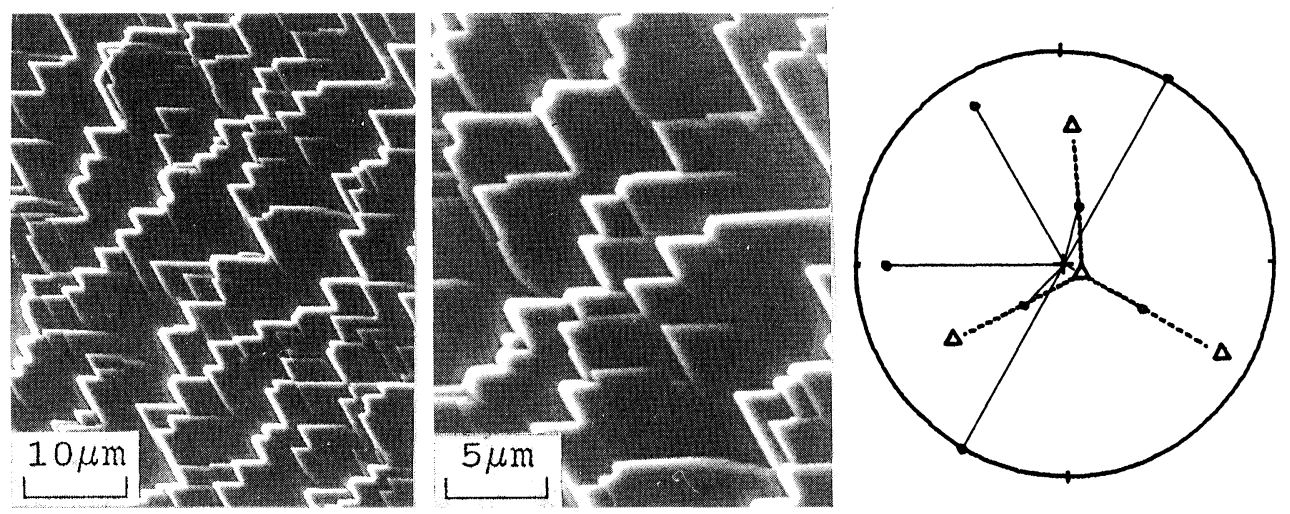

orientation 37

$\begin{array}{llll}E: & 23.8 & 60.6 & 55.8\end{array}$

M: $\quad\left(\begin{array}{lll}72 & 49 & 49\end{array}\right) \quad\left[\begin{array}{lll}35 & -87 & 35\end{array}\right]$
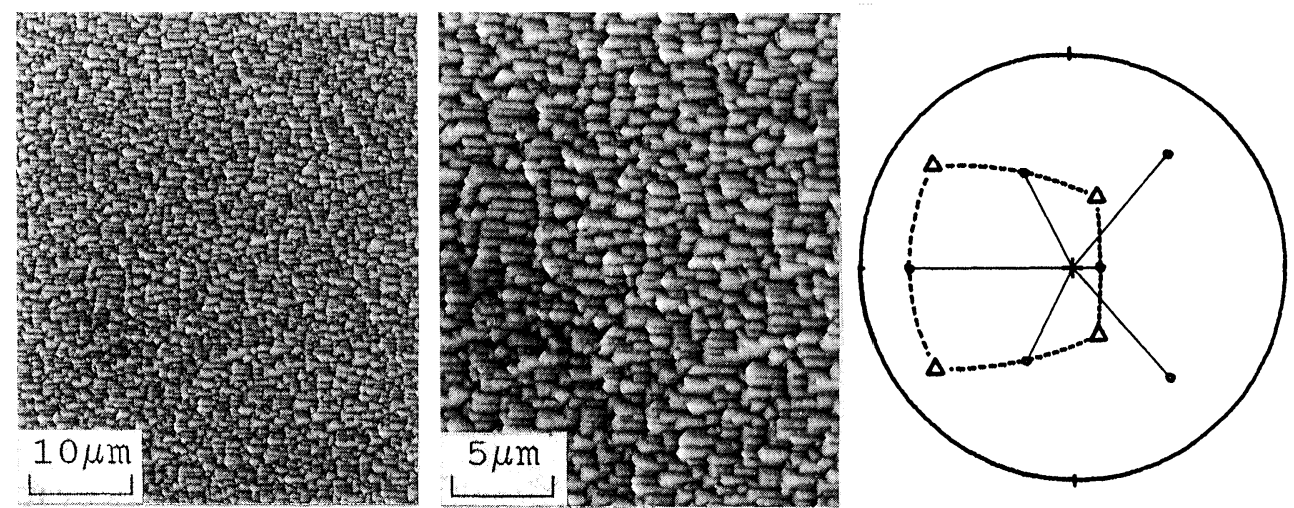

orientation

E: $\quad \begin{array}{llll}0.0 & 60.1 & 90.0\end{array}$

M: $\left(\begin{array}{lll}87 & 0 & 50\end{array}\right)\left[\begin{array}{lll}0 & -1 & 0\end{array}\right]$ 

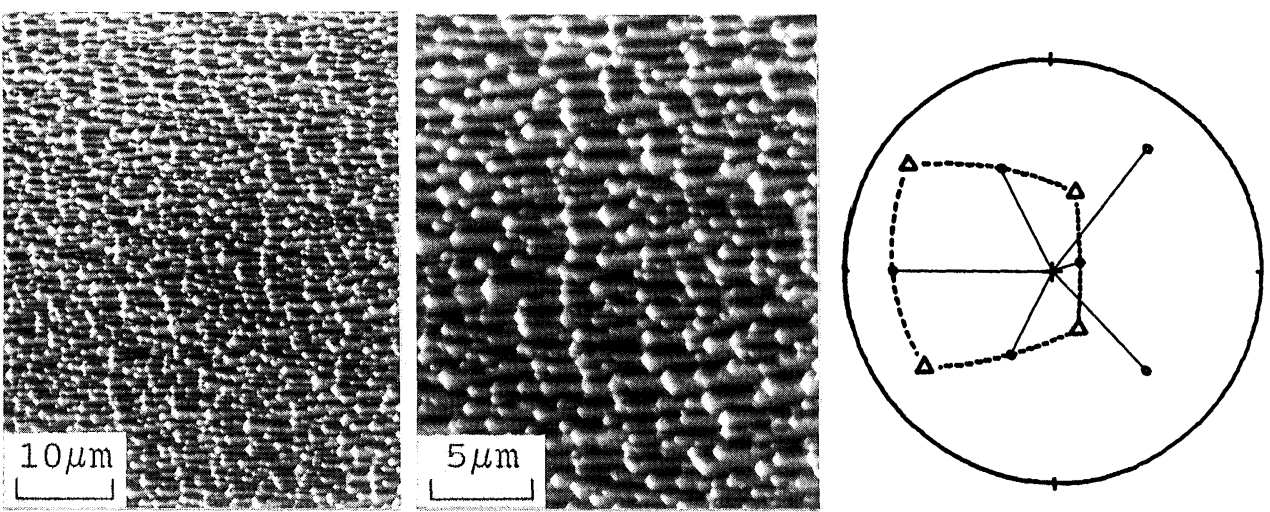

orientation 42

$\begin{array}{llll}\text { E: } & 3.9 & 59.9 & 84.7\end{array}$

M

M: ( $\left.\begin{array}{lll}86 & 8 & 50\end{array}\right)$

$\left[\begin{array}{lll}6 & -100 & 6\end{array}\right]$
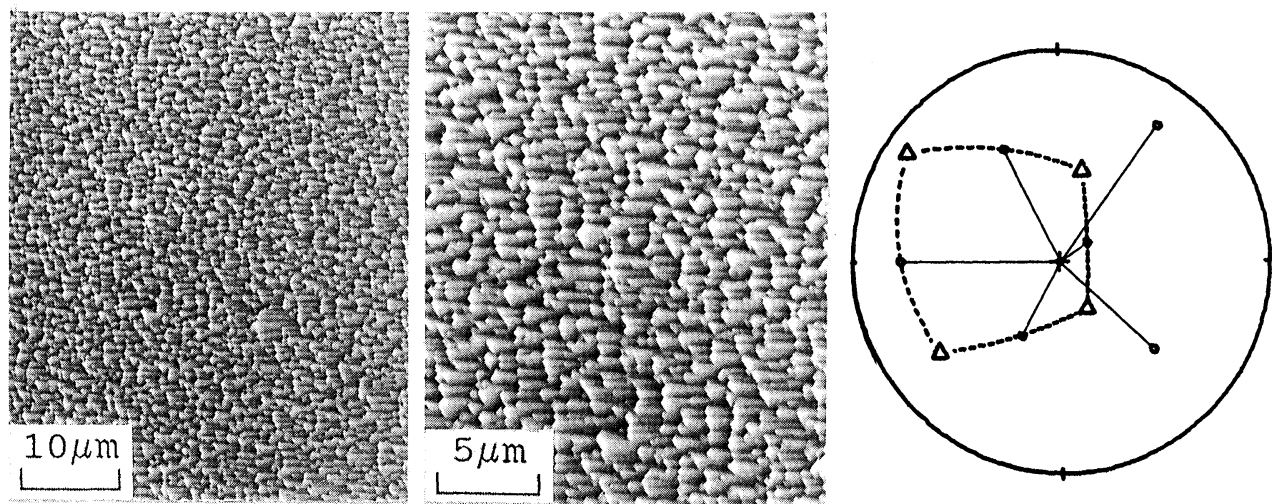

Orientation 43

$\begin{array}{llll}E: & 8.1 & 60.8 & 78.8\end{array}$

M: $\left(\begin{array}{lll}86 & 17 & 49\end{array}\right) \quad\left[\begin{array}{lll}12 & -98 & 12\end{array}\right]$
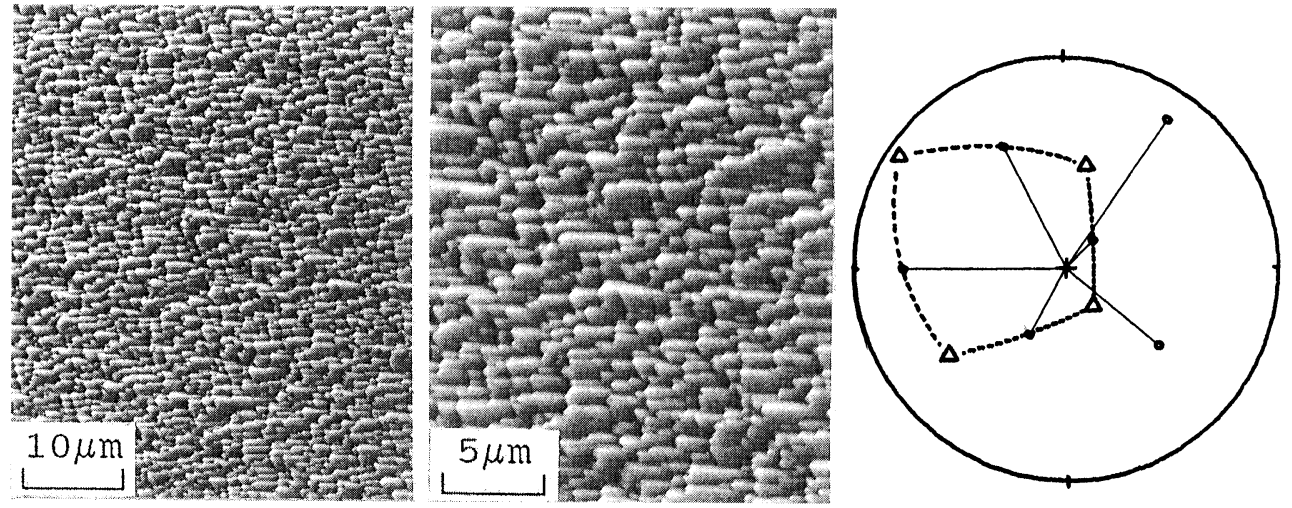

orientation

44

$\begin{array}{llll}\mathrm{E}: & 12.0 & 61.3 & 73.4\end{array}$

M: $\left(\begin{array}{lll}84 & 25 & 48\end{array}\right) \quad\left[\begin{array}{lll}18 & -97 & 18\end{array}\right]$ 


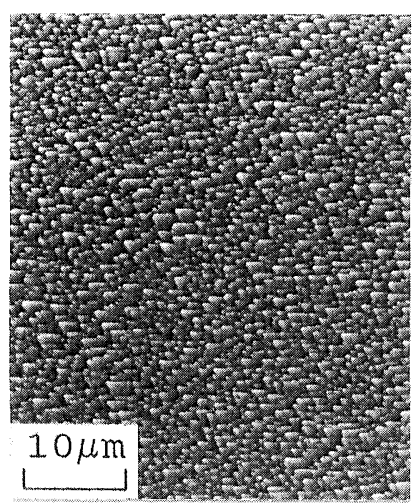

orientation 45

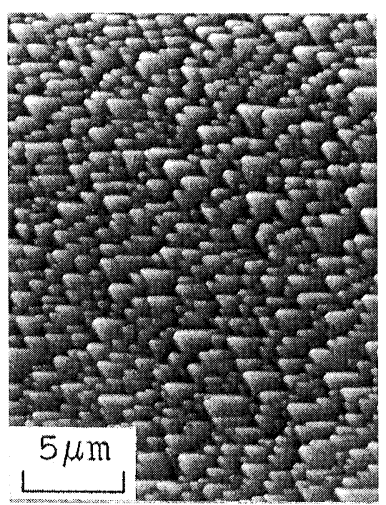

$\begin{array}{llll}\mathrm{E}: & 15.8 & 62.5 & 68.1\end{array}$

M: $\left(\begin{array}{lll}82 & 33 & 46\end{array}\right) \quad\left[\begin{array}{lll}24 & -94 & 24\end{array}\right]$

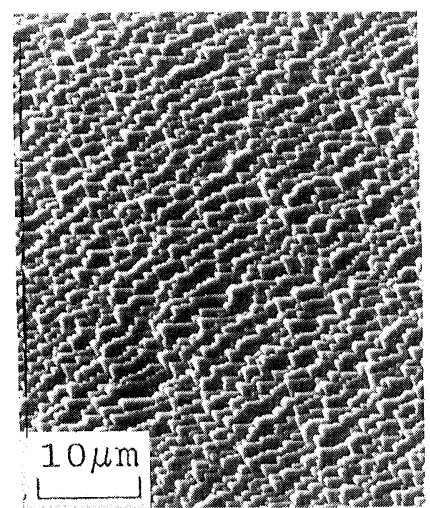

Orientation 46
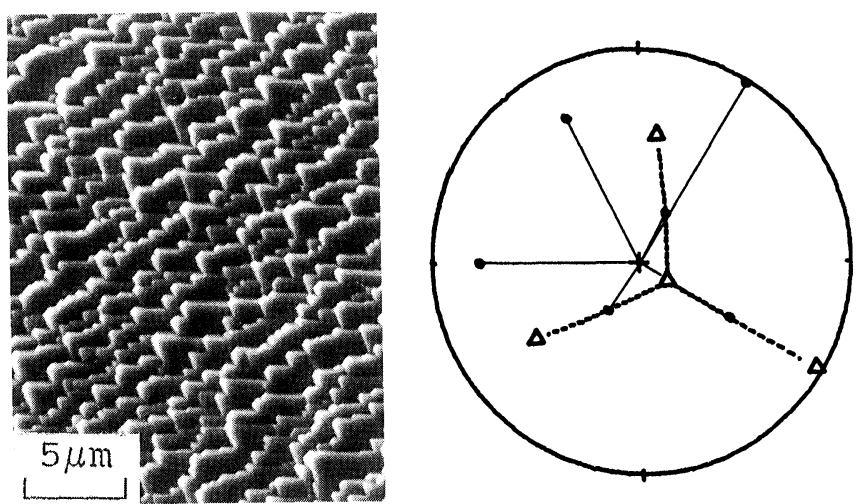

E: $\quad \begin{array}{lll}19.5 & 63.9 & 62.9\end{array}$

M: $\left(\begin{array}{lll}80 & 41 & 44\end{array}\right) \quad\left[\begin{array}{lll}30 & -91 & 30\end{array}\right]$
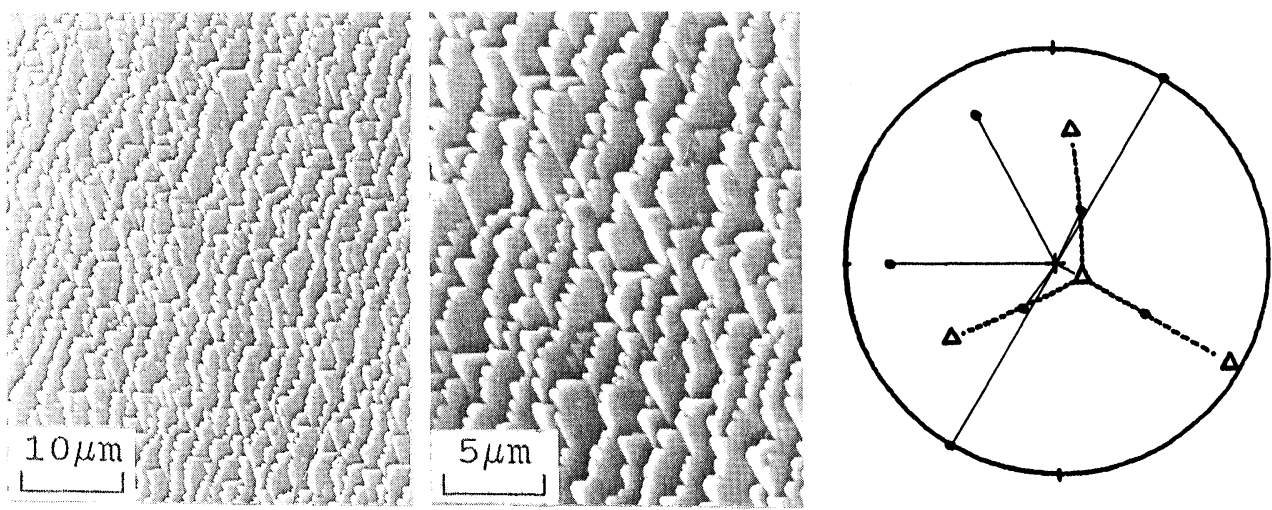

orientation

$$
\begin{aligned}
& \begin{array}{llll}
\text { E: } & 21.0 & 63.8 & 60.6
\end{array} \\
& \text { M: }\left(\begin{array}{lll}
78 & 44 & 44
\end{array}\right) \quad\left[\begin{array}{lll}
32 & -89 & 32
\end{array}\right]
\end{aligned}
$$



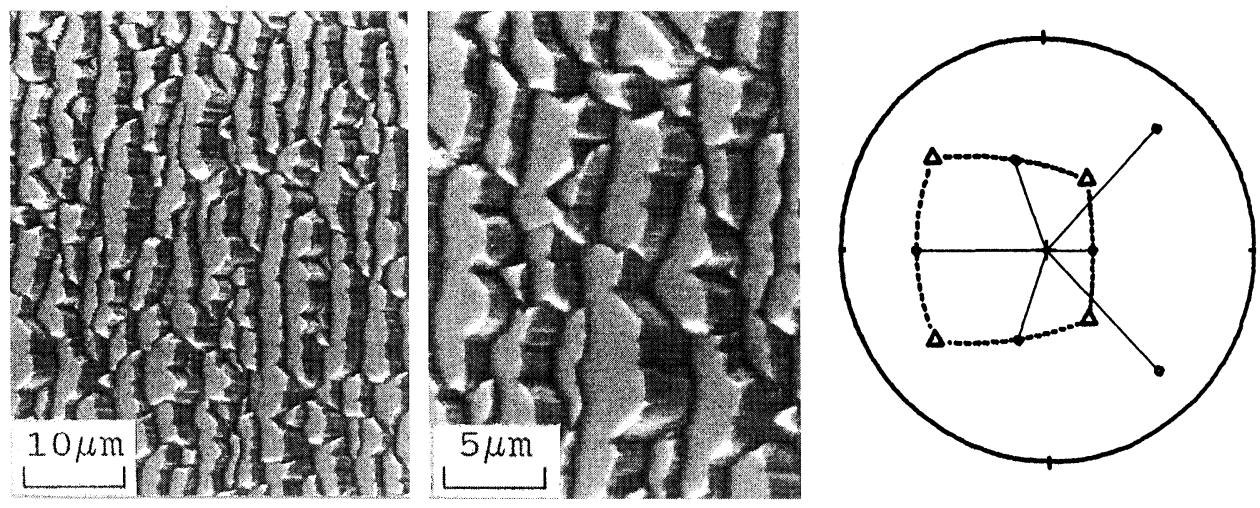

Orientation $51 \quad$ E: $\quad \begin{array}{llll}0.0 & 70.1 & 90.0\end{array}$

M: $\left(\begin{array}{llll}94 & 0 & 34\end{array}\right)\left[\begin{array}{lll}0 & -1 & 0\end{array}\right]$
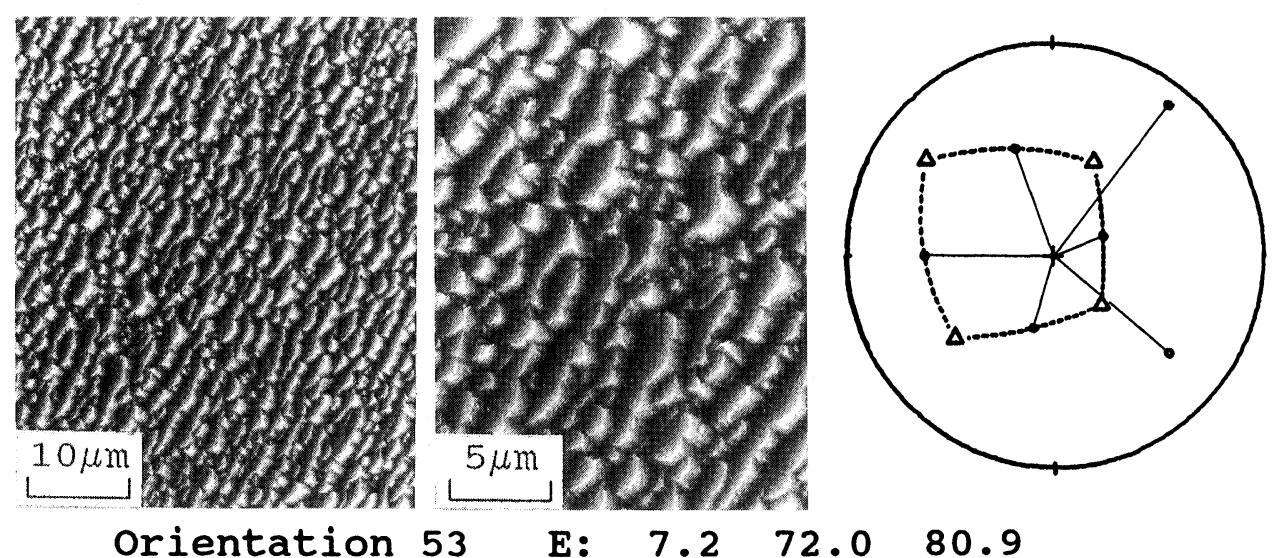

Orientation 53

E: $\quad 7.2 \quad 72.0 \quad 80.9$

M: $\left(\begin{array}{lll}94 & 15 & 31\end{array}\right) \quad\left[\begin{array}{lll}12 & -99 & 12\end{array}\right]$
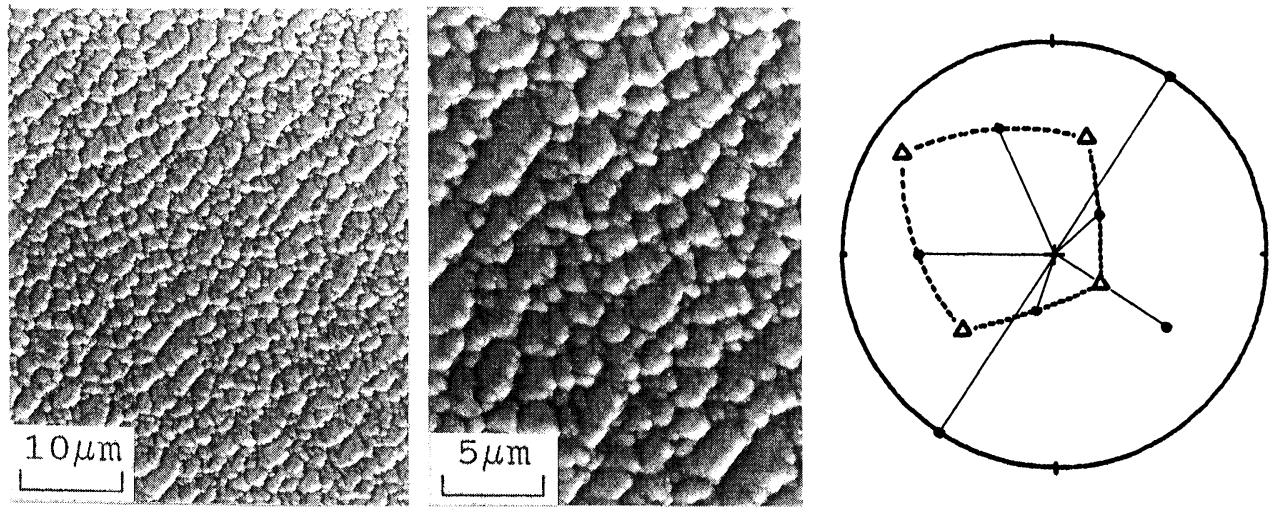
orientation 55

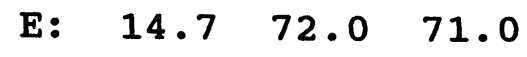

M: $\left(\begin{array}{lll}90 & 31 & 31\end{array}\right) \quad\left[\begin{array}{lll}24 & -94 & 24\end{array}\right]$ 

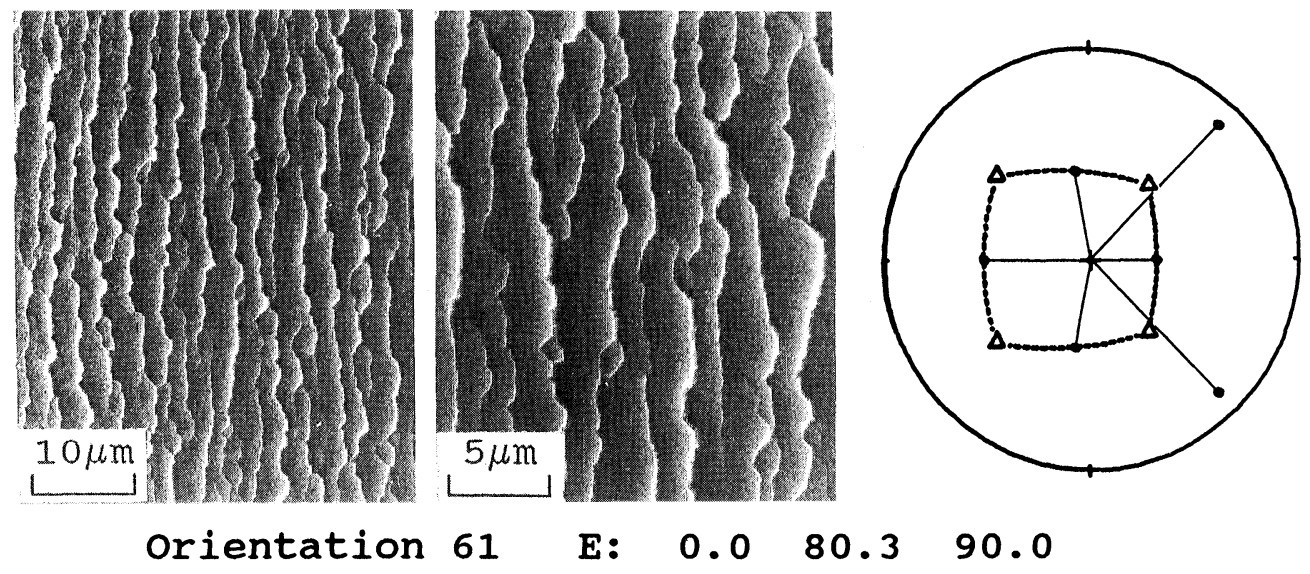

E: $\quad \begin{array}{llll}0.0 & 80.3 & 90.0\end{array}$

M: $\left(\begin{array}{lll}99 & 0 & 17\end{array}\right)\left[\begin{array}{lll}0 & -1 & 0\end{array}\right]$
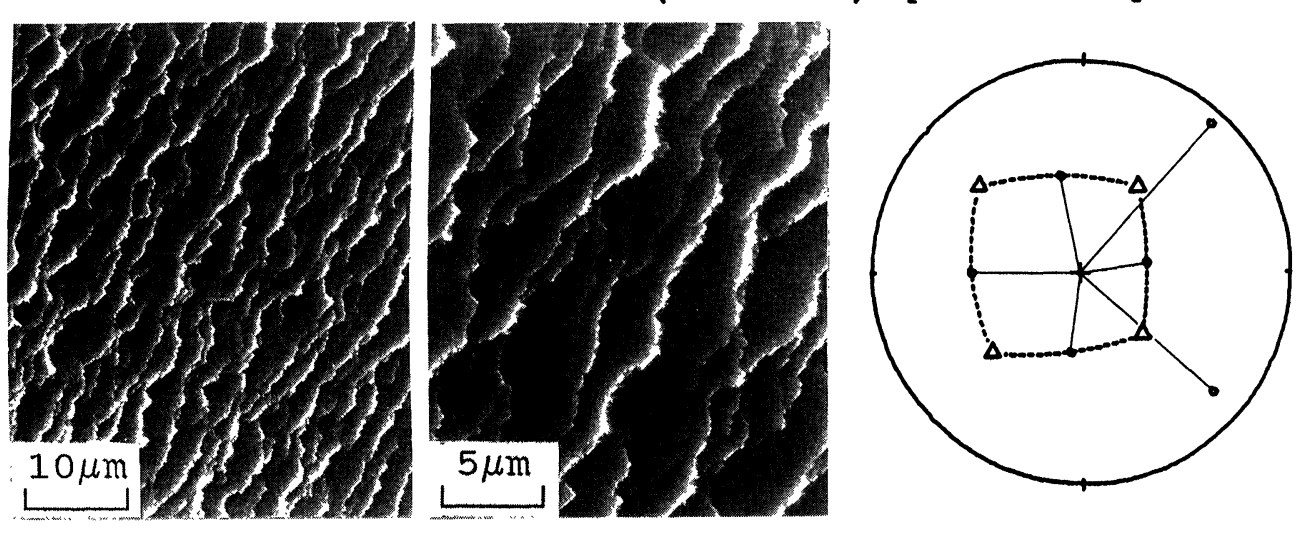

orientation 62

E: $\quad 3.5 \quad 80.2 \quad 85.9$

M: $\left(\begin{array}{lll}98 & 7 & 17\end{array}\right) \quad\left[\begin{array}{lll}6 & -100 & 6\end{array}\right]$
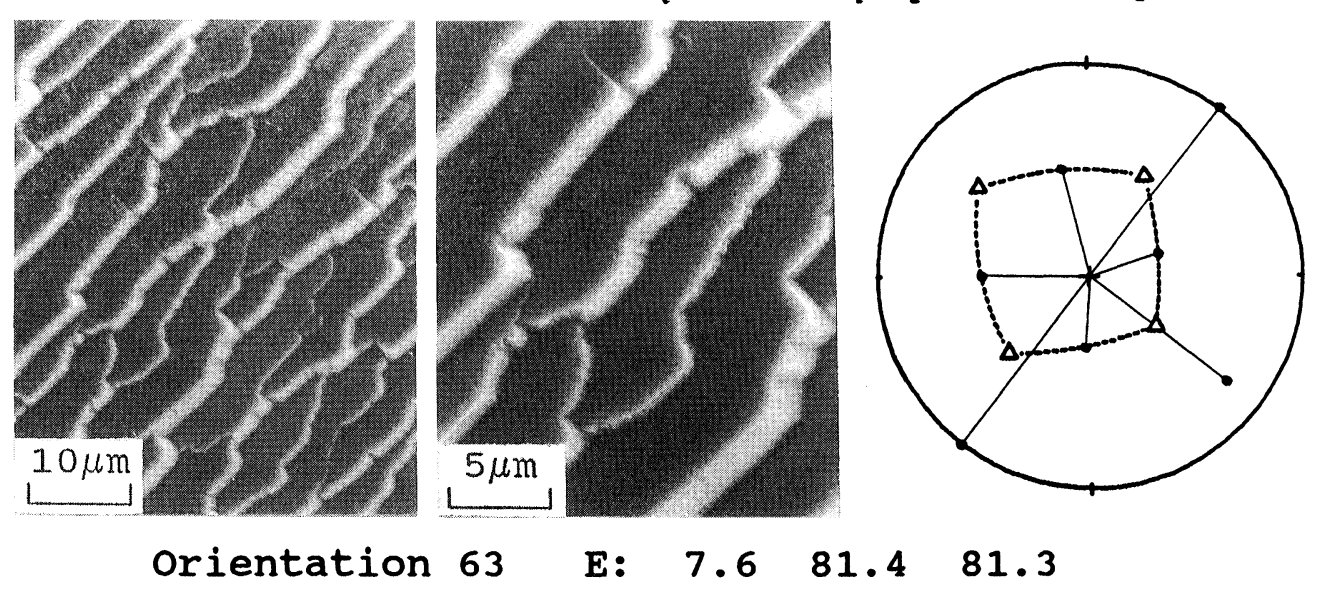

E: $\quad \begin{array}{llll}7.6 & 81.4 & 81.3\end{array}$

M: $\left(\begin{array}{lll}98 & 15 & 15\end{array}\right) \quad\left[\begin{array}{lll}13 & -98 & 13\end{array}\right]$ 

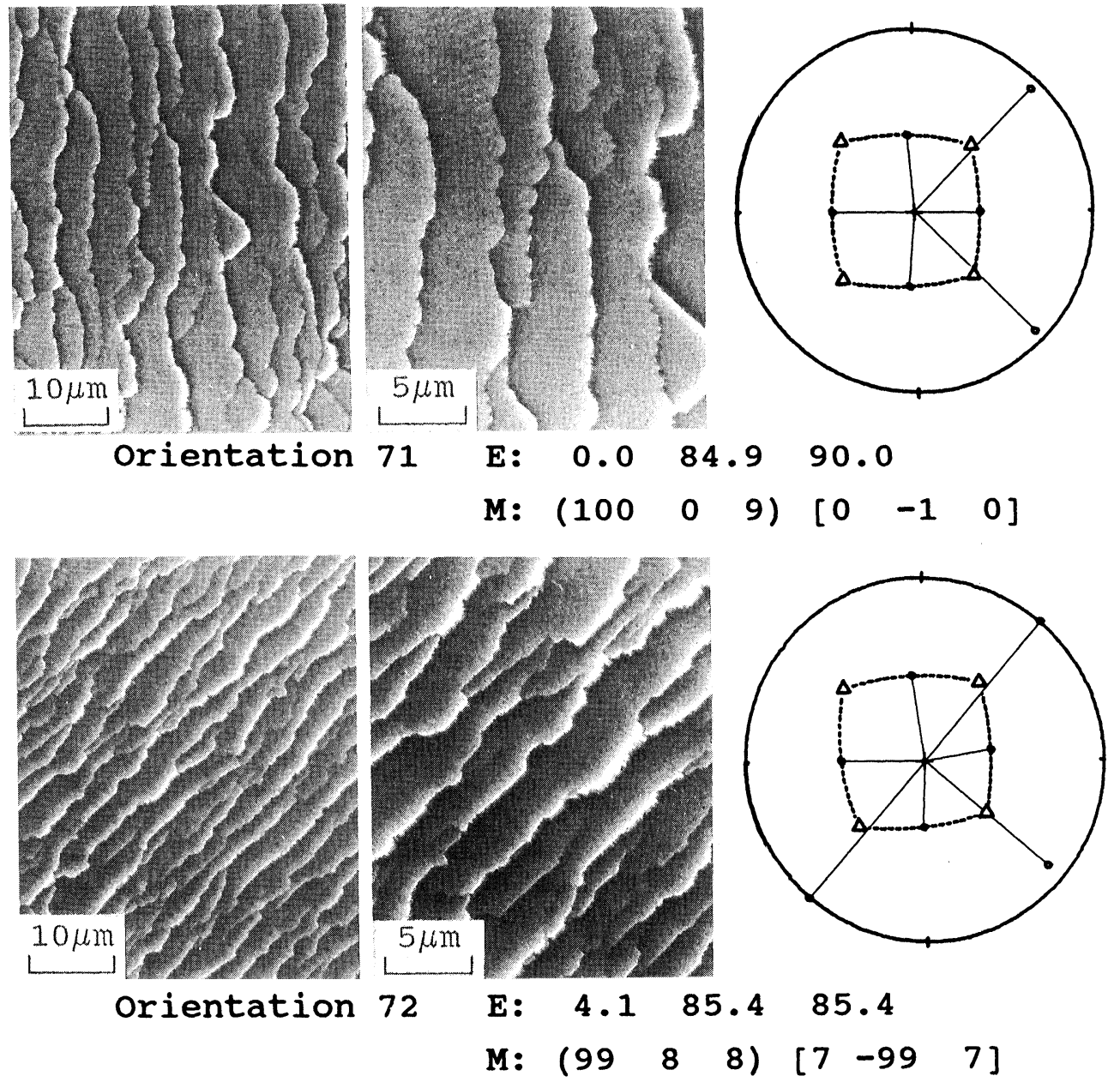

.485 .4

M: $\quad(99 \quad 8$

8) $\left[\begin{array}{lll}7 & -99 & 7\end{array}\right]$
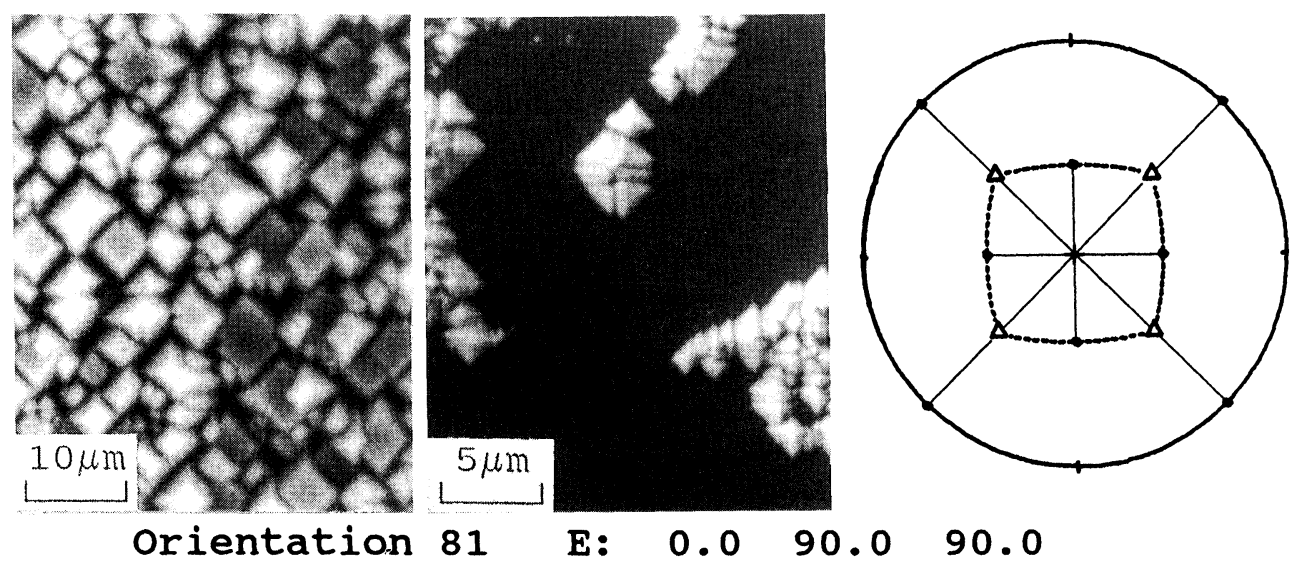

81

E: $\quad 0.0 \quad 90.0 \quad 90.0$

M: $\left(\begin{array}{lll}1 & 0 & 0\end{array}\right)\left[\begin{array}{lll}0 & -1 & 0\end{array}\right]$ 